\title{
MAX AUB EN DJELFA: LO GIERTOY LO DUDOSO (28 DE NOVIEMBRE DE 1941-18 DE MAYO DE 1942)
}

\section{De París a DJelfa}

Hoy se conocen con precisión las circunstancias y los hechos que llevaron a Max Aub de París a Djelfa (Argelia) ${ }^{1}$. A fines de enero de 1939, el escritor español forma parte del equipo de rodaje de Sierra de Teruel que, después de haber trabajado con Malraux en España, cruza en camión la frontera franco-española, logrando evitar las humillantes experiencias de la retiraday de los campos de internamiento en las playas del Rosellón. Al llegar a París, ciudad de su nacimiento (en una familia francoalemana de origen judío, 1903) y de su infancia hasta 1914, Aub se reúne con su mujer y sus hijas que se encontraban allí desde 1937, año en que el escritor había ocupado el cargo de agregado cultural en la embajada española. A pesar de numerosas relaciones y fuertes apoyos, pronto empieza a experimentar las difíciles condiciones de existencia de un exiliado sin recursos económicos ${ }^{2}$, desprovisto además de las autorizaciones para residir en territorio francés. Confiado en que el haber nacido en París le será de alguna ayuda, intenta regularizar su situación, pero topa rápidamente con las severas exigencias de la adminis-

1 Véanse Gérard MaLgat, Max Aub y Francia o la esperanza traicionada, Renacimiento, Sevilla, 2007, pp. 82-103 y José María NAHarro-Calderón, "Max Aub: à la recherche du nom perdu", en Max Aub, Manuscrit Corbeau, tr. R. Marrast, Mare Nostrum, Narbonne, 1998, pp. 143-198. De ambos trabajos saco lo principal del período que precede a la transferencia de Aub a Djelfa.

${ }^{2}$ En aquella época, parece haber vivido de las ayudas proporcionadas por Malraux a cambio de los últimos trabajos para el montaje de Sierra de Teruel (Malgat, op. cit., pp. 84-85.) 
tración francesa, reforzadas en aquellos meses anteriores a la guerra: se ordena una encuesta policial sobre el solicitante indocumentado y, mientras tanto, se le autoriza a permanecer en Francia. El 11 de octubre, un informe del Ministerio del Interior, evocando la participación de Aub en "una reunión comunista que tuvo lugar en la Casa de la Mutualidad"3 dos años antes, el 10 de junio de 1937 , concluye en la imposibilidad de permitirle residir en la capital francesa, decisión que aparentemente no surte efecto inmediato ya que Aub y su mujer permanecen en París 4 . Pero ese primer informe policial va a ser la causa de su ingreso, con nombre y apellido, en el temible laberinto de los ficheros policiales y administrativos.

Profundamente español y europeo, estrechamente vinculado a ciertos círculos intelectuales y artísticos parisinos y sin percibir, quizás por ello, el carácter peligroso de su estancia en París al final del año de 1939, Aub no siente la necesidad de otro exilio en EE. UU. o México y elabora proyectos editoriales con algunos intelectuales o hispanistas franceses. Sin embargo, mientras tanto, una denuncia española anónima transmitida al Ministerio Francés de Asuntos Exteriores por José Félix de Lequerica, embajador franquista en París, pone en marcha un peligroso engranaje policial basado en una ficciôn $n^{5}$ que, en los ficheros de la policía, se autoalimenta. En conformidad con los miedos que pesan sobre la sociedad francesa en aquella época de la dróle de guerre y sobre los estamentos de un régimen republicano agónico (el de la Tercera República), se va construyendo un personaje aubiano que bien poco tiene que ver con la realidad. Se perfila una silueta esbozada con rasgos imaginarios o deformados, oscurecidos voluntariamente con tonos de la paleta usada para la elaboración de los retratos-robots de aquellos años: los del "israelita", el "extranjero indeseable", el "comunista notorio" y "peligroso", el alemán antifascista subrepticiamente naturalizado español por un gobierno "rojo" en medio de la confusión de una guerra civil ${ }^{6}$; traje cortado a medida que seguirá vistiendo al

${ }^{3}$ Ibid., p. 86.

${ }^{4}$ Por razones económicas, sus hijas se hospedaron en familias de acogida o estuvieron algún tiempo en campamentos de vacaciones (ibid., p. 85.)

${ }^{5}$ Ficción detalladamente analizada por MALGaT (op. cit.) y NAHARRoCALderón: "Max Aub y los «universos concentracionarios»", en Max Aub: enracinements et déracinements, éds. M.-C. Chaput et B. Sicot, Université Paris X-Nanterre, 2003, pp. 105-126.

${ }^{6}$ Retomo los términos de la nota verbal del embajador español al 
escritor durante toda la Segunda Guerra Mundial y gran parte de la Cuarta República francesa ya que, exiliado en México, no conseguirá visado para volver a París hasta fines de $1956^{7}$.

A consecuencia de la denuncia española, Aub es detenido en París el 5 de abril de 1940, internado en el estadio Roland Garros (cuyas instalaciones y canchas de tenis servían de centro de detención) y transferido el 30 de mayo al campo disciplinario de Le Vernet d' Ariège, al sur de la ciudad de Toulouse. Pese a los esfuerzos de sus amigos franceses y españoles para conseguir su liberación, ésta sólo se logrará en noviembre del mismo año, es decir después de la invasión alemana y la instalación del régimen colaboracionista de Vichy en la llamada "zona libre", lo cual supone para el escritor un contexto político y represivo de mayor peligrosidad que el anterior. Sometido a arresto domiciliario en Marsella, Aub retoma sus contactos, especialmente con Malraux. Se relaciona con las organizaciones americanas (Hebrew Inmigrant-Colonisation-emigdirect-HICEM-y Emergency Rescue Committee) que brindaban ayuda a los refugiados $^{8}$, pero también con Gilberto Bosques, cónsul de México cuya constante y atrevida actividad, en la línea de la política de Cárdenas en favor de los republicanos españoles, permitió a miles de ellos acogerse a la hospitalidad mexicana ${ }^{9}$. Para protegerle

Ministerio Francés de Asuntos Exteriores: "afin que des mesures puissent être prises", L'equerica añadía: "que le ressortissant allemand Max Aub (Israélite), qui fut naturalisé espagnol par le Gouvernement rouge, lors de la guerre civile, et qui se trouve actuellement en France, selon les informations fournies à cette Ambassade, est un communiste notoire d'activités dangereuses" (cf., en sendas ediciones de Aznar Soler: Max Aub, Diarios [1939-1962], Alba Editorial, Barcelona, 1998, p. 43 y Diarios 1939-1952, CONACULTA, México, 2000, p. 35; también en MaLGAT, op. cit., p. 90). En total contradicción con la realidad, esta nota verbal reproduce con bastante fidelidad la denuncia anónima y manuscrita recibida por la embajada española (reproducida por Aznar Soler, Diarios [1939-1962], p. 44 y Diarios 1939-1952, p. 36; MALGAT, op. cit., p. 89). A pesar de haber nacido en una familia judía, Aub era agnóstico. Nacionalizado español en 1924, sus orígenes (francés de nacimiento, parisino hasta 1914), y su bilingüismo perfecto son características de un "extranjero" bastante atípico en Francia. Miembro del Partido Socialista Obrero Español desde 1929, sus relaciones con los comunistas siempre fueron más o menos complicadas.

${ }^{7}$ Malgat, op. cit., p. 137.

${ }^{8}$ Cf. NAHARro-Calderón, "Max Aub: à la recherche du nom perdu", p. 165.

${ }^{9} \mathrm{El}$ marco jurídico de la actividad de Bosques a favor de los republicanos españoles lo conformaba el acuerdo bilateral franco-mexicano del 22 de agosto de 1940 (Daniel Peschanski, La France des camps. L'internement, 19381946, Gallimard, Paris, 2002, p. 221). 
y facilitar sus desplazamientos y contactos, Bosques le consigue un título de agregado de prensa. El escritor dispone en aquella época de todos los visados necesarios para viajar a México o a $\mathbf{E E}$. UU. Sin embargo, beneficiado de apoyos que cree eficaces, relativamente libre en sus movimientos, sigue rechazando la idea de exiliarse al otro lado del Atlántico y permanece en la zona libre. En posesión de un salvoconducto, a principios de junio de 1941 Aub se desplaza a varios lugares de la costa mediterránea para entrevistarse con Gide, con Matisse y con el poeta Louis Aragon, comunista, miembro influyente de la Resistencia. Pero el 5 de junio, en Niza, se le detiene y permanece en la cárcel de dicha ciudad hasta el 21 del mismo mes. Diversas intervenciones, la de Bosques especialmente, serán necesarias para su liberación. Esta detención vuelve a poner en marcha la maquinaria represiva: un nuevo informe policial con fecha del 28 de junio de 1941 repite, acentuándolas, las falsas acusaciones anteriores ${ }^{10} \mathrm{y}$ el 5 de septiembre, otra vez detenido, Aub se ve conducido por segunda vez al campo de Le Vernet d'Ariège desde el cual será transferido al de Djelfa a fines de noviembre de 1941.

Esta transferencia se lleva a cabo en el marco de la política de Vichy consistente desde el inicio de $1941^{11}$ en alejar de Francia, llevándolos a África del Norte, "a unos 5000 franceses y extranjeros particularmente peligrosos"12, "cabecillas extremistas irreductibles"13. Con este propósito, entre marzo de 1941 y agosto de 1942 se organizan unas diez expediciones a Argelia con un total de 1390 presos $^{14}$. La séptima, la que incluía a Aub, estaba planeada para "76 extranjeros indeseables" 15 provenien-

${ }^{10}$ Reproducido por Malcat, op. cit., p. 100.

${ }^{11}$ Las primeras transferencias empiezan, según PESCHANSkı, en noviembre de 1940 y se deben a la iniciativa de Jean-Pierre Ingrand, representante en París, ante las fuerzas de ocupación, del Ministro del Interior del gobierno de Vichy (op. cit., pp. 306-307).

12 "...environ 5000 Français et étrangers particulièrement dangereux..." (carta del "Ministre Secrétaire d'État pour l'Intérieur à M. l'Amiral de la Flotte Darlan”, 15 de febrero de 1941, Archivo Nacional, París, AN F 715111 , en adelante, $A N$ París) .

13 Carta del 17 de febrero de 1941: "LiAmiral de la Flotte F. Darlan, Secrétaire d'État à la Marine à M. le Général d'Armée, Ministre Secrétaire d'État à la Guerre", "Objet: transfert de meneurs extrémistes irréductibles de la Métropole dans le Sud algérien" (AN París).

14 Peschanski, op. cit., p. 308.

15 "76 étrangers indésirables", "Convois à destination de l'Algérie" (AN París). 
tes de Le Vernet d'Ariège, 38 alemanes, 14 ex austriacos (sic), 8 húngaros, 4 ex checoslovacos (sic), 1 apátrida, 8 rumanos y 3 españoles ${ }^{16}$. Fuertemente vigilado, este grupo debía salir de Le Vernet el 24 de noviembre en direcciơm a Rivesaltes, hacer noche en el campo de internamiento de esta ciudad y, el 25, dirigirse a Port-Vendres para embarcar rumbo a Argel donde la llegada estaba prevista el 27 de noviembre.

En un texto poco conocido, "Campo de Djelfa, Argelia", Aub relata, ya con algunos toques literarios, ese viaje en las calas del barco Sidi Aïcha y la llegada a Argel:

Salimos de Port Vendres al anochecer, fuera del puerto nos quitaron las esposas. Un médico francés deportado pidió permiso para que nos dejaran subir al puente de cinco en cinco, de diez en diez. Ni siquiera contestaron. No veíamos más que el relucir de las bayonetas de la infantería de marina, de guardia en lo alto de la escalera. Debían verse las costas de España. Éramos dos los españoles de la expedición, hubiésemos querido ver tierra española, yo la sentía correr por mi costado, físicamente. Llegamos a los tres días a Argel, maravilla malva al amanecer. Nos encerraron en un viejo bastión, nos dieron bien de comer. Hasta ese momento nos habían trasladado el equipaje (yo no puedo viajar sin libros, además llevaba bastante ropa y mis manuscritos). A la noche, los franceses marcharon, iban a un campo cercano, fue una despedida emocionante. A las seis de la mañana nos hicieron formar para ir a la estación ${ }^{17}$.

${ }^{16}$ Cf. "Note à Monsieur le Directeur du Personnel et de l'Administration de la Police", Vichy, 15 de noviembre de 1941, firmada por "Le Directeur de la Police du Territoire et des Étrangers" (AN Paris). Estas cifras y la que concierne la totalidad del grupo (76) podrían no corresponder sino a previsiones. El informe de un inspector de los campos, después de una misión en Argelia en la primavera de 1942, hace referencia a 68 personas llegadas a Djelfa el 28 de noviembre de 1941 ("Djelfa", André Jean-Faure, AN París). Para Aub, eran setenta, "dos españoles, el resto alemanes, checos, húngaros, polacos" "Campo de Djelfa, Argelia", archivo Max Aub, Biblioteca Daniel Cosío Villegas de El Colegio de México, caja 19, volumen 50; a continuación, las referencias a este archivo se abreviarán como BDCV, indicando caja y volumen). Inédito hasta hace poco, este tex to ha sido publicado recientemente por CÉSAR NÚÑEZ: "Max Aub en «el país del viento": algunos poemas del denominado ciclo de Djelfa (1941-1942)", en Homenaje a Max Aub, eds. J. Valender y G. Rojo, El Colegio de México, México, 2005, pp. 351-355. También lo reproduce Eloísa Nos ALdÁs en El testimonio literario de Max Aub sobre los campos de concentración en Francia (1940-1942), Castellón, 2001, p. 109, tesis inédita consultable en: http:/ /www.tdx.cesca.es//eloisanos.pdf:

17 "Campo de Djelfa, Argelia" (doc. cit.) Una versión literariamente más elaborada de este relato se puede leer en "Yo no invento nada", texto incluí- 
Luego, en el mismo texto, después de un largo viaje en tren, al llegar a Djelfa de noche, en el otoño de la alta meseta argelina -“...nunca habíamos visto tantas estrellas. Hacía mucho frío"-, interviene el episodio del abandono forzoso de las maletas, imposibles de transportar sin ayuda en aquellas circunstancias. Se hace entonces cargo de los presos un personaje-Gravelle-que éstos no tardarían en conocer mejor a sus expensas y de quien reciben la orden de dirigirse a paso gimnástico hacia el campo con el equipaje al hombro. Aub protesta:

-No puedo llevar mi equipaje.

-Déjelo. A mí me tiene sin cuidado. Pero nadie vendrá a por él ¿̇me entiende? Andando canallas.

Abandoné mi equipaje, con una sola maleta al hombro eché a andar. A los cien metros varios menos decididos cargados a más no poder empezaron a pararse. El hombre de la boina a fustazo limpio los hacía adelantar. Cayeron varios y puntapié va y viene los obligó a seguir. La carretera se vio sembrada de maletas...

Antes de la relativa publicidad que le granjearía el poemario de Aub ${ }^{18}$, Djelfa no era sino un oscuro topónimo del interior de Argelia $^{19}$. En 1930 su población rondaba los 3000 habitantes. No

do en No son cuentos [1944]; reed.: Enero sin nombre. Los relatos completos del Laberinto mágico, Alba Editorial, Madrid, 1994, p. 321.

${ }_{18}$ Diario de Djelfa, con seis fotografias, edición privada, México, 1944 y Diario de Djelfa, Joaquín Mortiz, México, 1970. En adelante, estas dos ediciones se abreviarán como $D j I$ y $D j 2$. Las citas se harán a partir de $D j 2$, indicando el título del poema y el número que se le atribuye en esta edición.

${ }^{19}$ La creación de una pequeña colonia agrícola en la vertiente norte de los montes Ouled Naíl, a más o menos 1200 metros de altitud y a trescientos kilómetros al sur de Argel en dirección a Laghouat y Ghardaïa, se remonta a 1850. Fue oficializada por un decreto de Napoleón III en 1861. En 1862, se terminó la edificación de una iglesia. Durante muchos años las diligencias fueron el único medio de transporte de pasajeros entre Argel y Djelfa, hasta 1921, año en que un ferrocarril de vía estrecha se terminó de construir. Contrariamente a lo que se piensa muchas veces, conviene tomar nota de que Djelfa no se encuentra en el desierto del Sahara. Las referencias al "desierto" en Diario de Djelfa son metonímicas. En cuanto al ferrocarril, termina en Djelfa, sin continuación hacia Laghouat, a pesar de que sí fue uno de los itinerarios barajados desde principios del siglo xx para el famoso y utópico proyecto "Mediterránco-Níger". No tiene, pues, sentido, a propósito de Max Aub y sus compañeros, escribir que se les hizo trabajar en la construcción del transahariano. Los que sí trabajaron en un tramo del nunca acabado proyecto colonial, a veces en condiciones pésimas, fueron los presos españoles 
sería muy superior a fines de 1941 cuando el escritor llegó de Le Vernet. Localidad aislada al sur de la meseta que bordea el Atlas sahariano, al final de una vía de ferrocarril, poco poblada pero con fuerte presencia militar (dos cuarteles), alejada de los grandes centros urbanos, ubicada en una zona esteparia casi desértica, Djelfa reunía todas las ventajas de la extraterritorialidad ${ }^{20}$ propicia a la instalación de un campo disciplinario en marzo de 1941, incluyendo condiciones climáticas particularmente duras en verano y en invierno. En la terminología de Vichy, el campo de Djelfa era un "Centro de estancia vigilada" ["Centre de séjour surveillé"], borroso eufemismo administrativo para un centro de detención en el que el trabajo no era "legalmente" obligatorio pero cuyo director, con el beneplácito de su jerarquía, había transformado en una especie de presidio, una "fábrica" ["usine"] escribiría en su informe de 1942 el inspector Jean-Faure con evidente satisfacción ${ }^{21}$. Mal protegidos de las inclemencias del clima, mal vestidos, peor alimentados y con escasos cuidados médicos, expuestos a las brutalidades de las autoridades del campo, los presos se veían obligados a trabajar para conseguir algún suplemento de alimentación, contribuyendo así, bien a pesar suyo, al enriquecimiento fraudulento de Jules César Caboche, comandante del campo. En Djelfa, paradójicamente, no trabajar venía a ser un castigo reservado principalmente a los ex brigadistas y a los judíos, a quienes se privaba así del necesario, aunque escaso, suplemento alimenticio. Este sistema (el casse-croûte como remuneración ${ }^{22}$ ) y el carácter relativamente benigno de algunas de las tareas impuestas a la mayoría de los presos, tal vez expliquen por qué los documentos archivados y los testimonios no dan cuenta de más de unas treinta o treinta

enganchados en los Grupos de Trabajadores Extranjeros (GTE), asignados al tendido de vías hacia Colomb Béchar, por un lado desde Bu Arfa (Marruecos) y, por otro lado, desde Kenadza (Argelia). Véase, al respecto, Búsqueda en la noche (Ediciones Nueva Era, Buenos Aires, 1957), novela de ARTUro EsTEVE que se desarrolla en la región de Bu Arfa y el testimonio (inédito) de Ángel Landa Sierra, miembro del GTE núm. 8, basado en Kenadza (fondo histórico del Ateneo español de México, caja 9, expediente 125).

20 Término utilizado por Georges Steiner y que AnNeTte Wieviorka retoma a propósito de Auschwitz: "Un lugar en alguna forma no inscrito en un territorio. Esta extraterritorialidad..." (Auschwitz, 60 ans après, Laffont, Paris, 2005, p. 12; la traducción es mía).

21 "Djelfa", doc. cit. (AN París).

22 Transcrito "cascrut" por Aub en el poema "Epitafio" (21). 
y cinco defunciones ${ }^{23}$ para una población que en los primeros meses de la existencia del campo parece haberse aproximado al millar de presos ${ }^{24}$. Aunque remiten a otro campo disciplinario, el de Le Vernet d'Ariège donde Arthur Koestler precedió a Aub,

23 Un documento elaborado en enero de 1944, cuando el "Tribunal d'armée d'Alger" (tribunal militar creado por De Gaulle) preparaba el juicio en el que tuvo que comparecer el comandante del campo, proporciona una lista de 35 presos muertos entre marzo de 1941 y junio de 1943 (fechas en que se abre y se cierra el CSS) sin que se sepa si dicha lista es realmente exhaustiva y si incluye las muertes que pudieron ocurrir fuera del perímetro del campo (Centre des Archives d'Outre-Mer, Aix-en-Provence, 9 H 116 120, en adelante CAOM). En México, en enero de 1943, Aub hablará de 57 muertos (de tifus) en 1941, cifra no respaldada por ningún documento referente a Djelfa ("Situación de los prisioneros y refugiados al final de 1942 en África del Norte”, BDCV, c. 4, v. 6). Probablemente más cerca de la realidad, al hablar del cementerio europeo del pueblo, donde se les daba sepultura a los muertos del campo, el poeta evoca unas treinta tumbas ("Ya hiedes, Julián Castillo", 9). Por su lado, Pablo de Azcárate -ex embajador del gobierno republicano español en Londres y entonces alto funcionario de la Sociedad de Naciones (SDN) - proporciona la misma cifra en una nota dirigida al "Director of the civil service of the grand headquarters of the allies in North Africa": "And finally, as a conclusion of an existence of suffering and privations, about 30 interned, in the full strength of their lives before being interned, have died, and now rest in the churchyard of Djelfa, dumb witnesses of the tragedy" (fondo Azcárate, MAE, Madrid, caja 53.) Sobre un total de aproximadamente 30 muertos, pero no inferior a 35 , parece ser que unos veinte fueron españoles. Una lista establecida por Aub, probablemente en 1944 con la intención de que pudiera encabezar Diario de Djelfa, incluye 18 nombres y la mención "muertos enterrados en Djelfa" (BDCV; lista publicada por NAHARRO-CALDERón, "Max Aub y los «universos concentracionarios»", p. 114, n. 29 y por C. NúÑEZ, art. cit., anexo 1, p. 350). También la reproduce Aub al principio de "Asamblea contra el terror nazifascista. Intervención del C. Max Aub, escritor español recién llegado de los campos de Djelfa y Argelia [sic], en la sesión del 15 de octubre de 1942, por la mañana" (BDCV, c. 19, v. 50). En la lista de enero de 1944, establecida por la autoridad militar francesa (doc. cit.), figuran 16 de los nombres recordados por Aub, pero otros 6 o 7 podrían corresponder a republicanos españoles.

${ }^{24}$ Después de alcanzar su nivel máximo al terminar el primer año de funcionamiento, la población del campo empieza a decrecer: en mayo de 1941, 919 internados; abril de 1942, 970; octubre de 1942, 855; diciembre de 1942, 798 ; marzo de 1943, alrededor de 700; junio de 1943, menos de 300 , transferidos al CSS de Berrouaghia en el momento de la transformación del campo de Djelfa en campo de prisioneros de guerra (cf. diversos documentos de archivos: CAOM, AN París y MAE en Madrid). Para junio del 41, Joseph Weil, citado por ANTONIO Soriano, indica la cifra de 1200 internos, cantidad que nunca aparece en los documentos consultados (Éxodos. Historia oral del exilio republicano en Francia, 1939-1945, Crítica, Barcelona, 1989, p. 224). 
unas líneas del escritor húngaro pueden ayudar a explicar ese nivel de mortalidad sin punto de comparación con el de los campos nazis. En las primeras (bastante citadas), señala el alto grado de miseria material de los campos franceses y lo dicho se puede aplicar a Djelfa: “...desde el punto de vista de la alimentación, de la instalación y de la higiene, Le Vernet se encontraba incluso por debajo del nivel de un campo de concentración nazi”. Pero en las siguientes (anteriores en su libro y sólo aparentemente contradictorias), Koestler lleva a cabo, en cuanto a la crueldad, una comparación en la que recalca con fuerza las diferencias de grado entre los campos de Vichy y los de los nazis -quizás no de naturaleza ya que todo se mide por el mismo termómetro (centígrado o Farenheit) de la infamia ${ }^{25}$ - y el húngaro era experto en el tema:

En el termómetro centígrado del Liberalismo, le Vernet se encontraba en el punto cero de la infamia; en el termómetro Farenheit de Dachau, todavía se encontraba a 32 por encima de cero. En le Vernet, los golpes eran un acontecimiento cotidiano; en Dachau, duraban hasta que la muerte llegara. En le Vernet, se mataba a la gente por falta de cuidados médicos; en Dachau, se la mataba voluntariamente. En le Vernet, la mitad de los prisioneros dormían sin mantas, a veinte grados bajo cero; en Dachau, se les encadenaba para exponerlos al frío ${ }^{26}$.

\section{EL PRESo MAX Aub}

En un campo de esas características generales, agravadas por el aislamiento, el clima, la poca protección de las tiendas de campaña (los "marabús" prestados por el ejército), en la noche del 28 de noviembre de $1941^{27}$, después de haber abandonado

${ }^{25}$ Sobre esta distinción, por cierto polémica, entre gradoy naturaleza, remito a DAvid Rousset, L'Unizers concentrationnaire, Hachette, Paris, [1965], p. 57.

26 Arthur Koestler, Scum of the earth [1941], La Lie de la terre, tr. J. Terracini, Charlot, Paris, 1947, pp. 154 y 148-149, respectivamente; la traducción al español es mía.

27 Nada documenta ni justifica la fecha del 12 de diciembre propuesta por E. Nos Aldés quizás al intentar corregir la del 12 de noviembre, error del autor o tal vez errata de la mecanógrafa al copiar "Diario de Djelfa, Argelia" (op. cit., p. 104). Una carta de Caboche al Comandante militar del Territorio de Ghardaia (29 de noviembre de 1941) confirma la llegada a la estación de Djelfa de 68 presos el día 28 a las ocho y media de la noche y proporciona la lista de los recién llegados incluyendo el nombre de Aub (CAOM). 
parte de su equipaje, incluyendo libros y manuscritos, empieza Aub una estancia que duraría hasta el 18 de mayo de 1942, o sea cinco meses y diecinueve días. Numerosos indicios y bastantes documentos hacen algo incomprensibles las dudas que todavía parecen existir en cuanto a la duración de esa estancia y llevan indefectiblemente a prolongarla hasta siete, ocho, incluso nueve meses ${ }^{28}$. Pero, constatar la relativa brevedad de ese internamiento en nada atenúa la peculiar percepción del tiempo que es la de los presos en semejantes condiciones y que Aub expresó uniendo su voz a la de Lope, "Siempre mañana y nunca ser mañana / la libertad que tanto se ansia" ("Al son de Lope", 37). Tampoco convendría olvidar que los meses de Djelfa fueron precedidos por los de Roland Carros (dos en 1941), de Le Vernet (siete en 1940 y tres en 1941), sin hablar de los quince días de su encarcelamiento en Niza.

Conocidos y publicados desde hace unos ocho o nueve años, varios documentos son claros testimonios de que el escritor español fue efectivamente liberado el lunes 18 de mayo de 1942 y que salió el mismo día por la mañana en dirección a Casablanca, vía Uxda, ciudad marroquí cerca de la frontera con Argelia; otros, inéditos, también lo confirman ${ }^{29}$. Las dudas se deben

${ }^{28} \mathrm{El}$ propio Aub habló (a bulto, noviembre-mayo) de una estancia de siete meses ("Asamblea contra el terror nazifascista. Intervención del C. Max Aub...") Por su lado, los estudiosos no se ponen de acuerdo. Dentro de los últimos en escribir sobre este período, E. Nos Aldás habla de "casi nueve meses" (op. cit., p. 108) y, sin embargo, en la página siguiente, añade: "El 18 de mayo de 1942 Aub sale de Djelfa”. Apoyándose en Miguel Ángel González Sanchís y Manuel Aznar Soler, NúÑEz alarga la estancia de Aub en Djelfa hasta "julio de 1942" (art. cit., p. 285 y n. 6); luego, señala, con razón, la datación problemática de los últimos poemas de Dj2 (ibid., p. 362, n. 2).

${ }^{29}$ Véanse: 1) la orden de liberación de Aub, firmada por Gaboche el 17 de mayo de 1942 (CAOM, publicada por Aznar Soler en Diarios [1939-1972] y Diarios 1939-1952, pp. 88 y 91, respectivamente); 2) la nota inédita mandada el 18 de mayo al Comandante militar del Territorio de Ghardaiia por la cual Caboche notifica oficialmente la salida de Aub: "J'ai l'honneur de vous rendre compte que le nommé Max Aub a été mis en route ce jour sur Casablanca, en vue de son émigration au Mexique" (CAOM); 3) una carta de Gilberto Bosques a Aub, con fecha del 18 de junio de 1942, enviada a Casablanca (c/o HICEM, rue du Pas-de-Calais) (Diarios [1939-1972], pp. 8990 y Diarios 1939-1952, pp. 92-93); otras cartas del epistolario conservado por la FMA (Fundación Max Aub, Segorbe, provincia de Castellón) probarían del mismo modo la presencia del escritor en Casablanca, quizás desde el 21 de mayo hasta su embarque el 10 de septiembre; 4) las fechas de algunos textos inéditos conservados en la BDCV: por ejemplo "Dolor" y el soneto "Espera" que llevan la indicación "Uxda 20-5-42" (c. 12, v. 36). Otro poema, sin título, 
principalmente a que las fechas que en Dj2 acompañan los últimos poemas (del 43 al 46 incluido) son engañosas ya que llevan a pensar que éstos fueron escritos dentro del campo después del 18 de mayo y hacen suponer que la liberación del autor pudo ser posterior al 5 de julio (fecha del poema 46 titulado "Visita"). Lo mismo ocurre con la fecha del último texto -"Mal día" (47), 8 de julio de 1942- escrito en Uxda según declaración del propio poeta en su "Nota para la segunda edición" 30. Tratándose de cuatro poemas seguidos, se descarta ahí la posibilidad de un simple error de datación, aunque parece haber muchos en el poemario $^{31}$, o de una mistificación intencional, posibilidad sin embargo nada ajena a lo que nos tiene acostumbrados el autor de Antología traducida, Imposible Sinaí o Jusep Torres Campalans. Cabe otra hipótesis, relacionada con el tono, el contenido y las intenciones de estos cuatro poemas anteriores al que fue escrito en Uxda. Algo tienen en común: denunciar nommalmente, con pelos y señales, y altas dosis de invectiva, sarcasmo e insultos a los responsables del campo: el director, "don Caboche" ("El palo entre las manos", 43), “...menos oue una piedra, / menos que una piltrafa, / menos que una joroba dromedaria, / menos que una meada" ("No tienes tú la culpa", 44); el responsable de la policía interna, Gravelle, insistentemente llamado "hijo de puta" en el "Romance de Gravela" (45) título que, para mayor inri, lleva clavado el nombre del siniestro personaje. Sin nombrar al coronel Lupy, el texto siguiente ("Visita", 46) es una obvia denuncia de la culpable ligereza con la que el más alto responsable directo de los campos en Argelia desempeñaba su labor de inspector, actitud que abría el camino a cualquier tipo

fechado el 21 de mayo y que empieza por "A mí me sorprendió siempre", en el que el poeta se queda absorto al tener "el Atlántico a [sus] pies". Luego estaría la serie de poemas escritos en Casablanca, como es el caso de "Medina de Casablanca" (16 de julio de 1942; c. 11, v. 33), del largo "Poema de Ain Sebaa" que va precedido por estas explícitas palabras del autor: "Este poema fue escrito en Ain Sebaa, a pocos kilómetros de Casablanca. A la salida de una larga cautividad en las altas mesetas del Atlas Sahariano, en junio de 1942" (BDCV, c. 9, v. 25; publicado por Arcadio López Casanova en MAX Aub, Obra poética completa, Biblioteca Valenciana-Generalitat Valenciana, Valencia, 2001, t. 1, pp. 395-406).

${ }^{30} \mathrm{Dj} 2$, p. 9.

${ }^{31}$ Contrariamente a las apariencias los poemas no están fechados rigurosamente. Sin que se sepa siempre la razón, las fechas que Aub les atribuye pueden variar bastante entre los distintos manuscritos y entre una edición y otra de Diario de Djelfa. 
de abusos ${ }^{32}$. Es muy probable que estos poemas, en los que Aub, blandiendo a su vez la fusta (la de las palabras), devuelve los golpes recibidos por los presos, no fueran "transcritos" en el campo. Podría corroborar esta hipótesis el hecho de que no figuran en ninguno de los manuscritos autógrafos conservados en España (FMA). Por consiguiente, para seguir (en parte) la corriente a Aub, habría que suponer que estos cuatro poemas con fechas problemáticas fueron compuestos o esbozados mentalmente en Djelfa, quizás aprendidos de memoria, recitados de noche bajo las tiendas para regocijo de sus compañeros españoles pero, por obvias razones de seguridad, sólo transcritos o terminados ulteriormente en Casablanca donde, precisamente, se encontraba el autor en las fechas indicadas y donde le sobró tiempo para ello, como para escribir otra serie de poemas. Nada impide tampoco, por lo menos de momento, pensar incluso que la versión escrita de estos poemas corresponde al período mexicano en que el poeta estaba preparando la primera edición de su poemario, la de 1944 en la que aparecen por primera vez. Hipótesis que no aclara la razón de su ausencia en los manuscritos archivados ${ }^{33}$.

En cuanto a las ocupaciones del preso Max Aub durante aquellos meses, se sabe que estuvo destinado al trabajo del cáñamo, materia prima abundante en la región de Djelfa ${ }^{34}$. Presentada como prueba irrefutable, la última de las seis fotografías incluidas en el poemario lo retrata debajo de una tienda marabú en compañía de otro internado, ocupados los dos en la fabricación de alpargatas, en concordancia con lo que reza, en la solapa de la edición de 1944, el comentario de dicha fotografía: "Mi trabajo: montar alpargatas". Aub formó parte, pues, del grupo de presos (unos 200 o 250) que trabajaron un tiempo dentro de las mismas tiendas donde vivían, relativamente

${ }^{32}$ En febrero de 1944, inculpado en el juicio abierto por el "Tribunal d'armée d'Alger" contra los responsables del campo de Hadjerat M'Guir, culpables de varios crímenes, Lupy quedó absuelto a pesar de que el fiscal (comisario del gobierno gaulista) requirió contra él dos años de cárcel (cf. el diario Alger Républicain, 4 de marzo de 1944).

33 Ya en prensa este artículo, y sin tiempo para modificar las líneas anteriores, me entero de la presencia de "Romance de Gravela" y de "Visita" en uno de los blocs de la FMA ("Notes", C 7-17), lo cual invalida, en buena parte, la hipótesis emitida.

${ }^{34}$ Aub llama "cáñamo" al esparto o "alfa" (voz de origen árabe que recogen pocos diccionarios), planta cuyo nombre permite, en francés, el chiste de "alfa-ville" que parece circular en la ciudad de Djelfa, por lo menos entre los aficionados al cine. 
protegidos por la tela del marabú, antes de que se les instalara en un barracón más adecuado. En la foto, ambos hombres trabajan sentados, apoyándose en las rodillas. Aub -llevando un sweater de cuello alto y una chamarra de cuero con cuello forrado de piel, tipo aviador- está sentado en el extremo de lo que podría ser un catre de tijera. Delante, una silla o un taburete con una cuerda. A su derecha, el palo central de la tienda cuyo pedestal sostiene una repisa redonda con algunos objetos de imposible identificación ${ }^{35}$. Sin embargo, a pesar del carácter aparentemente indiscutible del documento visual y de la fuerte aserción autorial (" $m i$ trabajo"), una parte importante de la actividad de Aub en Djelfa queda excluida de esta imagen que se ofrece como prueba fehaciente y del comentario que la acompaña. Según precisiones aportadas por el autor en "Campo de Djelfa, Argelia", documento sólo publicado (parcialmente) en 1943, en una revista mexicana bastante olvidada, bajo el título "YYo no invento nada!", también ocupó otras funciones, las de secretario de la enfermería: “¿La enfermería! Djelfa es el país del viento. El viento entra en la enfermería por todas partes. Nieva. ¡Cuántas veces he tenido que dejar de inscribir enfermos, morados los dedos...!"36. Esta cita poco difiere de las líneas correspondientes del texto conservado en la BDCV. Pero, al corregir la puntuación y la sintaxis de su frase en el texto publicado, Aub también borra lo que en el documento inicial aparece en forma

${ }^{35}$ En el campamento del Grupo de Trabajadores Extranjeros instalado en las inmediaciones de Bu Arfa (Marruecos, en la vía de ferrocarril hacia Colomb Béchar, Argelia) donde va a parar el protagonista de Búsqueda en la noche se utilizaban las mismas tiendas. Así describe su interior el narrador: "La caldereta, el bidón de agua de cinco litros y el cazo... algunos platos, cucharas, tarritos y la lámpara de acetileno que acostumbraban a colgar de clavos en el mástil y de una pequeña plataforma de madera de medio metro de radio fijada al palo central, como un anillo, a una altura de dos metros" (A. ESTEVE, op. cit., p. 57). En el interesante sitio de internet (voila.fr/espana36) se pueden ver ocho fotografías del campamento de Bu Arfa tomadas por Sinforiano Rodríguez, republicano español. ANDRé MoINe, en la Déportation et la résistance en Afrique du Nord (1939-1944) (Éditions Sociales, Paris, 1972), publica dos fotografías del campo de Djelfa y una del fuerte Caffarelli en las que aparecen claramente las tiendas "marabouts".

36 Segunda entrega de "YYo no invento nada!" (Revista Todo, México, 1 de abril de 1943, núm. 499), publicación que debo a la gentileza de James Valender. Obviamente, "Campo de Djelfa, Argelia" constituye una especie de borrador de esta entrega. El cuento, "Yo no invento nada", escrito en diciembre de 1942 y publicado en 1944 en No son cuentos, no reproduce el contenido de "Campo de Djelfa, Argelia". 
mucho más explícita: "Nieva jcuántas veces en la enfermería he tenido que dejar de inscribir enfermos, fui unos meses secretario de la misma, morados los dedos...!"37, como si no quisiera dejar totalmente al descubierto las huellas de una ocupación que representaba, en comparación con la situación de la mayoría de los presos, un evidente privilegio, parecido sin embargo al que tuvieron algunos escritores en los campos nazis o en el Gulag. $\mathrm{O}$ como si, al mismo tiempo, estas "huellas" estuvieran ahí (en el archivo y en la Revista Todo) para que los investigadores de hoy las fueran rastreando con el fin de establecer la exactitud de los hechos: juego tal vez no tan improbable por parte de quien escribía en Campo francés, casi en la misma época: “...todo deja huella, en hueco o en relieve, sirviendo para el futuro -si lo hay"38. Aunque se puede suponer el orden cronológico en que se sucedieron las dos ocupaciones (primero el esparto, luego la enfermería), no se sabe cuánto tiempo tuvo Aub que dedicarse a una y a otra. Lo probable, sin embargo, es que ya a principios de marzo (o quizás antes si se tienen en cuenta sus alusiones al frío de la enfermería donde se le quedaban "morados los dedos"39) fungía como secretario de la misma, gozando entonces

37 "Campo de Djelfa, Argelia" (doc. cit.; las cursivas son mías).

38 "Nota", Campo francés [1945], Alfaguara, Madrid, 1998, p. 14. A ello también apunta el aparente cuidado con que Aub diseminó las huellas, dividiendo en dos partes su archivo personal como para dificultar el trabajo de los investigadores y dejando algunas indicaciones ambiguas sobre lo que se podría publicar o no. Una de ellas ya llamó la atención de NúÑez, perfecto conocedor y estudioso del archivo de la BDCV. Se trata de una anotación manuscrita que encabeza el poema inédito "Silva de fallas" (19-3-42): "No se publique nunca. Podría romperlo, no puedo. MA" (art. cit., p. 357). Pero hay otra al inicio de una larga lista (tres folios manuscritos) de poemas, inéditos en su gran mayoría: "Para no publicar nunca sin ser revisados por mí: M. A." (BDCV, c. 14, v. 41). Es imposible saber si la prohibición incluye todos los títulos o sólo los que van subrayados. Pero, por un lado, muchos de estos poemas están transcritos a máquina y, por otro lado, ¿qué valor podían cobrar dichas anotaciones si, como opina Núñez con bastante razón, "es posible que las transcripciones [fueran] hechas en los mismos días en que el autor preparaba sus papeles para donarlos a la BDCV" (art. cit., p. 286), es decir hacia el final de su vida? Cabe suponer que Aub dudaba probablemente menos de lo que él mismo decía del interés de sus poemas: aunque declara que podría romper los que considera malos, no lo hace; aunque prohibe publicar algunos sin previa revisión por su parte, los conserva, transcritos, y muchas veces corregidos.

${ }^{39}$ Véase también el poema "Enfermería" (BDCV, c. 14, v. 41) recientemente publicado por C. NÚÑ̃E, art. cit., pp. 339-341. 
de condiciones relativamente propicias a su intenso trabajo de creación poética. En "El limpiabotas del Padre Eterno", Aub, por boca de Celestino Grajales, repite y completa la información con una breve descripción de su puesto de trabajo: "Yo estaba allí, en lo que se llama la enfermería... A la entrada, a la derecha, debajo de la ventana una mesa coja, un cuaderno, un tintero, un palillero. Ése era mi sitio" 40 .

Por otro lado, sorprende la revelación según la cual el escritor habría tenido que cumplir algún castigo en el llamado "campo especial" 41 . En dos documentos de la BDCV, escritos poco después de su llegada a México el 1 de octubre de 1942, Aub alude a sus varias estancias en ese recinto de castigo o de aislamiento para "los tontos, los locos, los más sucios, los presuntos rateros" $\$ 2$. Sin dar detalles, declara el 15 de octubre: "he tenido

40 "El limpiabotas del Padre Eterno" [1955], Enero sin nombre. Los relatos..., p. 304.

${ }^{41}$ La expresión "campo especial" designa, dentro del campo, un perímetro de treinta metros por treinta, también rodeado de alambradas, destinado a aislar o castigar. Existían lugares parecidos en la mayoría de los campos franceses, impuestos desde mayo de 1939 por una circular del ministro de Interior, Albert Sarrault (véanse, Gregory Tuban, Les séquestrés de Collioure, Mare Nostrum, Perpignan, 2003, p. 102 y Geneviève Dreyfus-Armand, L'Exil des républicains espagnols en France. De la guerre civile à la mort de Franco, Albin Michel, Paris, 1999, p. 69 y, por ejemplo, el testimonio novelado de JAUMe SADERRA I RIERA, Esgarrinys deifilferrada [somnis confinats], Ediciones El Paisaje, Aranguren, Vizcaya, 1989, p. 109). "Cuadrilátero", "hipódromo" o "picadero" parecen haber sido algunas de las palabras más empleadas para nombrarlos en otros campos. Púdicamente, el informe ya citado del inspector Jean-Faure no menciona el campo especial (tampoco las celdas del fuerte de Caffarelli). Los archivos del CAOM no dicen gran cosa del indigno perímetro donde en mi opinión fueron sacadas algunas de las fotos de Diario de Djelfa (véase mi art.: "Max Aub et la fictionnalisation des traces: questions sur les photographies de Diario de Djelfa", Tigre, 2006-07, núm. 15, 59-79). Una huella, eufemística y elíptica, pero que confirma el uso profiláctico del campo especial contra la mberculosis, aparece, sin embargo, en un informe del coronel Lupy dirigido al Gobernador General de Argelia el 5 de septiembre de 1941: "J'ai visité également le quartier où se trouvent quelques incurables: faibles d'esprit, tuberculeux, dont la présence constituait un danger pour leurs camarades. Le médecin a dû se contenter de les isoler dans le camp, et il est certain que plusieurs d'entre eux seraient mieux à leur place dans un asile ou un sanatorium" (CAOM). En marzo de 1943, unos cinco meses después del desembarco de los aliados en África del Norte, lógicamente el campo especial parece haber desaparecido: no lo mencionan los diputados comunistas Henri Martel y Antoine Demusois en sus informes del 6 y del 25 de marzo de 1943 (fondo Azcárate, MAE, Madrid, caja 53).

42 "Campo de Djelfa, Argelia" (doc. cit.) 
el honor de ir al campo especial más de una vez" 43 y lo repite en una ocasión parecida en marzo de 1943: "No me salvó del campo especial el ser socialista, lugar generalmente reservado a los raterillos, homosexuales y comunistas" 44 . Evidentemente, en la medida en que al secretario de la enfermería no se le puede aplicar ninguna de las características requeridas para recaer en tan desastroso perímetro, uno se queda con la curiosidad. También con las dudas en cuanto al castigo reivindicado y a sus eventuales motivos. A no ser que Aub haya querido llevar hasta esos extremos su papel de testigo, arreglándoselas para conocer por dentro el campo especial y, de cerca, a algunos de sus inquilinos habituales (Dorca, Casanada, el Madriles, futuros personajes), cuyo estado en Diario de Djelfa prefigura el de los "musulmanes", los Musulmänner en el argot de los campos nazis" ("Toda una historia", "j / campo especial", 19). Autoimposición comprensible si se tratara de las celdas del fuerte Caffarelli situado en el pueblo de Djelfa, pero aparentemente innecesaria en el caso del campo especial ubicado a la vista de todos según parece.

Lo cierto es que, tanto para poder dar a su diario poético el contenido testimonial que tiene, como para escribir luego, en México, los cuatro discursos tan abundantes en informaciones precisas sobre el campo de Djelfa, leídos ante la Asamblea contra el poder nazifascista, Aub tuvo que transformarse en observador atento de lo que ocurría a su alrededor y, para lo que obviamente no pudo presenciar y sin embargo relata, en receptor no menos atento de los testimonios de sus compañeros. Es de suponer que su trabajo en la enfermería, lugar probablemente

43 "Asamblea contra el terror nazifascista. Intervención del C. Max Aub..." (doc. cit.).

44 "En un acto en contra del terror nazi-fascista. Marzo 1943" (BDCV, c. 11, v. 34). Este texto y el anterior se presentan como discursos preparados por Aub para sus intervenciones en dicha asamblea mexicana sobre la que no tengo informaciones. Ignoro si fueron publicados en la prensa del Distrito Federal. Sin embargo, otro ("Situación de los prisioneros y refugiados al final de 1942 en África del Norte", BDCV, c. 4, v. 6), leído ante "el Comité permanente de la asamblea contra el terror nazifascista" reunido el 13 de enero de 1943 en el Hotel Majestic, si fue ampliamente difundido al día siguiente en El Nacionaly, en forma más breve, en El Universal. Un cuarto texto con las mismas características figura en la BDCV: "Situación de los refugiados que están en África" (c. 4, v. 6).

45 Véase, por ejemplo, Grorgio Agamben, Quel che resta de Auschwitz [1998], Ce qui reste d'Auschwitz, tr. P. Alferi, Rivages Poche-Petite Bibliothèque, Paris, 2003, esp. pp. 178-187. 
bastante visitado a pesar de sus increíbles deficiencias, le ofreciera la posibilidad de conocer a muchos presos con los que, de otra forma, no hubiera tenido la oportunidad o la posibilidad de conversar.

\section{ESCRIBIR EN EL CAMPO}

Por otra parte, también andaría bastante ocupado, desde su llegada a Djelfa, en redactar y mandar a múltiples corresponsales (Bosques, amigos y conocidos, autoridades francesas) cartas relativas a asuntos diversos o a su liberación ${ }^{46}$. Algunas ya han sido publicadas por Aznar Soler ${ }^{47}$ o por Malgat como ésta dirigida al Gobernador general de Argelia el 28 de febrero de 1942, escrita en francés y a máquina:

\section{Monsieur le Gouverneur Général de l'Algérie}

\section{Excellence,}

Je soussigné AUB Max, ressortissant espagnol, ai l'honneur de solliciter de votre haute bienveillance mon transfert à Casablanca, ou mon visa de sortie pour le Mexique, et ceci appuyé en [sic] les faits suivants:

Je suis en possession d'un visa mexicain, sur ce même document il est apposé un visa de sortie de France, aujourd'hui périmé.

Je dois embarquer à Casablanca vers le 20 mars sur le vapeur "Sawthone", où mon passage est retenu et payé, comme vous pouvez vous en rendre compte par les lettres ci.jointes.

Monsieur le Consul Général du Mexique en France a déjà eu l'honneur de vous télégraphier en vous demandant les ordres que je viens solliciter aujourd'hui de votre esprit de justice bien connu.

Trouvez ici, Excellence, l'expression de mes sentiments les plus respectueux.

Signé: Max Aub

Camp de Djelfa, 28 février $1942^{48}$.

46 “...cerca de cuarenta cartas relativas a su situación van a llegar o salir de Djelfa a lo largo de seis meses" (MaLGaT, op. cit., p. 104).

47 Véanse Diarios (1939-1972) y Diarios 1939-1952, pp. 87 y 90, respectivamente.

48 "Al Señor Gobernador General de Argelia / Excelencia: / Como firmante de esta carta, AUB Max, de nacionalidad española, tengo el honor de 
En Djelfa, Aub estaba implicado también en actividades de tipo cultural que no dejan de recordar prácticas constantes de los republicanos españoles en los campos de Francia. Según ciertos especialistas, dio clases de alfabetización usando para ello los pocos libros que tenía a mano ${ }^{49}$. Además, evocando la capacidad inventiva de sus compatriotas, Aub habla de "pequeñas fiestas" que, incluso en Djelfa y a pesar de las apariencias, los presos conseguían organizar. Tal vez se refiera a ciertos actos de "resistencia" que, en la adversidad más extrema, los españoles siempre supieron organizar para celebrar los aniversarios de los grandes acontecimientos políticos anteriores a la guerra civil: proclamación de la República (14 de abril de 1931), victoria electoral del Frente Popular (16 de febrero de 1936) y principio de la lucha contra el golpe franquista (18 de julio de 1936). Recuerda, desde México:

Pasado mañana hará un año tuvimos en Djelfa una gran fiesta. Pudimos repartir para todos un plato de macarrones con atún. El atún era portugués llegado a nosotros por la solidaridad internacional. Igual pudimos hacer para el 14 de abril, para el 16 de febrero, para el 18 de julio. Gimnasia rítmica, teatro al aire libre, bandas de música y hasta corrida de toros ante los ojos impotentes y atónitos del mando... ${ }^{50}$.

Pero se trataba también de reuniones clandestinas, más arriesgadas y por consiguiente susceptibles de represalias:

... fiestas, porque aún en los días más negros, del menos comer, del mayor frío o calor, no ha faltado nunca entre nosotros el es-

solicitar de su gran benevolencia mi transferencia a Casablanca, o mi visado de salida para México, y esto, apoyándome en los hechos siguientes: / Estoy en posesión de un visado mexicano, documento en el que figura un visado de salida de Francia, hoy caduco. / He de embarcar en Casablanca hacia el 20 de marzo en el vapor «Sawthone», en el que mi pasaje está reservado y pagado, como puede usted darse cuenta por las cartas adjuntas. / El señor Cónsul General de México en Francia ya tuvo el honor de mandarle un telegrama pidiendo las órdenes que hoy vengo a solicitar de su espíritu de justicia bien conocido. / Le manifiesto, Excelencia, la expresión de mis sentimientos más respetuosos. / Firmado: Max Aub / Campo de Djelfa, 28 de febrero de 1942" (CAOM; MALGAT, op. cit., p. 107).

${ }^{49}$ Según IgNacio Soldevila, Aub estaba en posesión de un diccionario y de un ejemplar de la poesía de Quevedo (El compromiso de la imaginación. Vida y obra de Max Aub, Fundación Max Aub, Segorbe, 1999, p. 42).

${ }^{50}$ Texto mecanografiado, sin título, sin fecha (BDCV, c. 4, v. 6.) 
píritu de victoria, el alegre espíritu de victoria. Por las noches en cada tienda de campaña habían $[s i c]$ cantos. Había -lo que no hay en México- teatro. Yo he hecho teatro en las tiendas de campaña con una manta tendida como telón y veinte hombres hacinados a mi alrededor, y cuando acabábamos de una pasábamos a otra, procurando huir de las rondas. Fiestas de circunstancias, cantos regionales, recitaciones de poesías. Recuerdos perennes de España. Ansia de volver, pero también, viva lección, negarse a volver vencidos. Como dije en una de esas poesías escritas entonces para ser recitadas entre alambradas, con un vigía avisor ${ }^{51}$.

Dentro de los textos de Diario de Djelfa, ninguno corresponde a lo que dice la última frase citada, pero el prólogo del poemario repite esta información en lo que toca a las lecturas clandestinas de sus poemas: "Solíamos leerlos, hambreados y lívidos a la luz de una mariposa cuidadosamente resguardada, bajo las tiendas de campaña, ocultándola de la crueldad imbécil de unos guardianes ciegos" 52 . En este ambiente de resistencia poética y clandestina, es fácil imaginar cómo sonarían a principio de venganza los poemas que figuran en las últimas páginas del poemario.

Sin embargo, a juzgar por la cantidad de su producción durante aquellos meses, lo que debió de ocupar la mayor parte del tiempo del preso Max Aub fue escribir sus poemas, quizás de noche a la luz de una mariposa, más probablemente de día en la mesa (caja) de la enfermería. En una carta en español dirigida el 3 de mayo de 1942 a Rolland-Simon, uno de sus contactos literarios en Francia, escribe: "Estoy aquí desde hace cinco meses, he trabajado bastante, le voy a mandar a usted versos, tan pronto como me conteste, para ver si nos ponemos de acuerdo para su traducción y su publicación en Fontaine..."53. Aunque

51 "En un acto en contra del terror nazi-fascista".

52 "Prólogo", Dj2, p. 7.

53 Carta publicada por Aznar Soler en Diarios (1939-1972) y Diarios 19391952, pp. 87 y 90, respectivamente. Rolland-Simon, a quien Aub conocía desde hacía varios años (MALGAT, op. cit., pp. 82 y 120), era miembro, con André Gide, André Chamson, Louis Aragon y otros, del Seeretariado de la Asociación Internacional de Escritores. Había traducido al francés, en 1938, el "Llanto por la muerte de Ignacio Sánchez Mejías" y publicado, en 1939 en París, Glose de Sainte Thérèse d'Ávila. En la época en que le escribió Aub, colaboraba con la revista Fontaine donde publicó "Souvenirs du ciel", poemas de Rafael Alberti (1942, t. 4, núm. 23). Fontaine. Revue Mensuelle de la Poésie et des Lettres Françaises, fundada en 1939 y dirigida por Max-Pol Fouchet, estaba vinculada a la Resistencia y se publicaba en Argel. Una de las decla- 
no se concretara, llama la atención este deseo de publicar en francés algunos poemas de Djelfa en una revista vinculada con la Resistencia, lo cual es una señal evidente de que el autor quería hacer de su diario poético un instrumento de denuncia. Pero lo que también interesa observar es que Aub, consciente de haber "trabajado bastante", considera que los poemas escritos ya han alcanzado una forma que los hace publicables.

La amplitud de ese trabajo de creación poética sólo se puede medir considerando primero que los veintisiete textos reunidos en 1944 no representan sino una parte muy reducida de lo escrito en aquella época. Aub lo señala en el prólogo de Dj1 (repetido en $D j 2$ ) y, al mismo tiempo, anuncia publicaciones ulteriores: "Aparece aquí una parte de lo escrito entonces; otras [poesías] de índole diversa, poemas hechos «adrede», buscando olvido en ejercicios retóricos u otros menos atados a lo inmediato, saldrán más adelante" 54 . Y así sucedió en octubre de 1949: no en forma de poemario o de plaquette, sino en Sala de Espera donde el poeta reunió, bajo el título general de "Cancionerillo africano", los textos a los que probablemente alude al hablar de "ejercicios retóricos" 55 ; ejercicios quizás pero a veces exitosos $y$, a pesar de su fresco sabor lírico, no tan ajenos como parece dar a entender su autor a la tonalidad general del poemario ${ }^{56}$. La edición de 1970 los incluirá todos ${ }^{57}$; no obstante, sus cua-

raciones editoriales ayuda a comprender el interés de Aub por publicar en esta revista: "Dans un monde qui se trahit lui-même, les poètes sont les seuls à demeurer fidèles à la notion d'humanité..." (agosto-septiembre de 1939, núm. 5). Rolland-Simon murió en Toulon, a manos de los alemanes, en 1944 (MALGAT, op. cit., p. 120, n. 228).

54 "Prólogo", Dj2, p. 7.

55 Sala de Espera, núm. 15, pp. 1-12. Este número de la revista unipersonal de Aub reúne efectivamente bajo el título indicado y en este orden: los 19 poemillas así denominados en Dj2 (29) y, además, "Amaneceres" (38), "Simún" (32), "Verano" (27), "Noches" (28), "Ocaso y luna" (35), "Día gris y noche despejada" (33).

56 Tema que desarrollo en "Journal de Djelfa et la littérature des camps", est. prel. a mi ed. bilingüe de Diario de Djelfa (publicación prevista para fines de 2007, Mare Nostrum, Perpiñán).

${ }^{57}$ NúÑEZ hace una interesante observación: basándose en una hoja manuscrita del archivo de la BDCV, "seguramente preparada para la publicación de Diario de Djelfa" y donde el poeta elaboró la lista de sus obras, señala que "junto al subtítulo «Verso» figuran, uno bajo otro, tres nombres: Djelfa, Cancionerillo africano, El poema de Aïn Sebaa". Luego añade: "Es difícil asegurar que Cancionerillo africano no aparece allí como subtítulo de Djelfa, pero la disposición de los nombres hace suponer que se trata de libros distintos, más 
renta y siete poemas representan menos de la mitad de todo lo escrito en las contrarias circunstancias del "Centre de séjour surveillé". Adicionando todos los textos, los inéditos y los de la segunda edición, César Núñez, riguroso conocedor del archivo de la BDCV, llega a un total de un centenar para lo que se suele llamar el "ciclo de Djelfa"58. Y si, dejando a un lado esta noción de "ciclo", aún poco precisa, nos limitamos a los poemas con fechas no ambiguas, realmente incluidas entre la llegada de Aub a Djelfa (28 de noviembre de 1941) y su salida (18 de mayo de 1942), la lista proporcionada por Núñez sigue siendo sorprendente, alcanzando ochenta y nueve títulos, o sea cuarenta y dos más que los que figuran en la edición de 1970. Naturalmente, la actividad poética de Aub en el campo sufre variaciones importantes. Más o menos un mes después de su llegada, al final de diciembre de 1941, escribe dos poemas, nueve en enero de 1942, la misma cantidad en febrero, treinta y nueve en marzo, diecisiete en abril y siete en la primera quincena de mayo. Otros seis, con fechas de junio o julio de 1942, incluyendo los cuatro colocados al final de $D j 2$, son, como ya se sabe, de difícil ubicación en este calendario. En marzo la actividad del poeta se hace pues particularmente intensa, casi diaria, con algunos nicos sorprendentes. Suponiendo, una vez más, exactas las fechas proporcionadas por el poeta, escribe en dos días (el 6 y el 9) el larguísimo poema narrativo "Toda una historia” ( catorce páginas en la edición de 1970!), el 13 componc cuatro, seis el 14, nes el 15 y, de nuevo, tres el 25 incluyendo "Cancionerillo africano", colección de diecinueve textos que, aunque breves, ocupan seis

aún cuando el poema «Cancionerillo africano» no fue incluido en la primera edición de Diario de Djelfa" (art. cit., pp. 357 y 358. )

58 Ibid., pp. 359-363. Mi propia evaluación llega a un resultado comparable, dejando de lado lógicamente los poemas que fueron escritos en Le Vernet d'Ariège, Niza, Marsella, Casablanca o, claro, México. Obviamente, y a pesar de lo que ocurre en el poemario de Aub, no creo que el ciclo denominado "de Djelfa" pueda incluir poemas escritos antes de la llegada del autor a dicho campo, ni después de su paso por Uxda. Sin embargo, las variantes en las fechas de los poemas no permiten un cómputo todo lo preciso que sería de desear. Por ejemplo, en la sección en la que Núñez reúne poemas de "datación ambigua o imprecisa", algunos títulos sí parecen corresponder a textos escritos en el campo. Creo que todavía se podría completar el inventario del archivo de la BDCV añadiendo algunos textos sin fecha o sin título, no siempre copiados a máquina, cuyo contenido está relacionado con la estancia del autor en Djelfa. Pero, de momento, será suficiente la evaluación de la que disponemos. 
páginas de la misma edición. La proximidad de la primavera, la mejora de las temperaturas, el renacer de la vegetación, fenómenos tan presentes en los textos de este período, pueden explicar en parte esta desbordante actividad en un mes muy celebrado en "Cancionerillo africano" donde, entre otras cosas, Aub escribe "marzo:jilguero / ¡cómo te quiero!" (29). Pero resulta casi imposible no relacionar también esta insólita producción marceña con el ocio y el confort (mesa y silla...), ciertamente relativos pero reales, que le proporcionaba su trabajo de secretario de la enfermería. A este respecto no carece de interés una corrección que aparece en una de las versiones de "Campo de Djelfa, Argelia”. Después de mencionar que muchas veces tuvo que "dejar de escribir" por culpa del frío reinante en la enfermería, como para dejar constancia de que sí le tocaba trabajar en dicho local, Aub corrige, a mano: "de inscribir enfermos" 59 : ¿corrección de un simple lapsus paronímico -escribir/inscribir-o autocensura ambigua ejercida ahí a sabiendas de que alguien, algún día, la sacaría a relucir?

\section{LOS MANUSCRITOS DE DJELFA}

Aub escribía en libretas, agendas o cuadernillos traídos de Le Vernet o conseguidos en Djelfa. Fáciles de llevar en un bolsillo ( $\sin$ que esto suponga la absoluta necesidad de esconderlos), en ellos tomaba todo tipo de notas o apuntes y esbozaba versos, trazaba los primeros borradores de sus poemas. Tras la división de su archivo en dos partes, la mayoría de esos soportes manuscritos se conserva en la Fundación Max Aub, uno en la BDCV ${ }^{60}$. No siempre fáciles de descifrar, dan testimonio de una actividad de escritura, si no incesante, por lo menos constante, y, con sus tachaduras y borrones, de los esfuerzos desplegados para alcanzar la expresión deseada. Constituyen el primer estado (incompleto) del manuscrito del poemario y de bastantes poemas del denominado "ciclo de Djelfa".

${ }^{59} \mathrm{BDCV}$, c. 19 , v. 50 ; las cursivas son mías.

${ }^{60}$ Véase en la FMA, por ejemplo y entre otras, las libretas C 7-1, C 7-6, C 715, C 7-17, C 7-18 y, en la BDCV, la libreta "Le pratique" (c. 12, v. 36) donde faltan las primeras hojas, aparentemente arrancadas, lo cual es el motivo de que empiece con el soneto "Espera" (Uxda, 20-5-42). Luego aparecen textos manuscritos de aquellos días, borradores de la época de Casablanca. 
Pero de Djelfa también proceden otros manuscritos cuyo soporte lo constituyen los dos cuadernos "L'incomparable" que figuran en el archivo de la FMA, habitualmente designados por M1 y M261. La cuidada presentación de los poemas transcritos en ellos, la clara letra del autor, el número reducido de correcciones, designan a este manuscrito como obviamente posterior al de los diversos cuadernillos. El primer cuaderno consta de treinta textos escritos entre el 25 de diciembre y el 11 de marzo de 1942, diecisiete de ellos incluidos luego en $D j 2$. El segundo recoge cuarenta y un poemas con fechas que van del 12 de marzo al 28 de abril del mismo año; quince encontrarán sitio en el poemario de 1970. Con pocas excepciones, estos textos, fechados y presentados a lo largo de los dos cuadernos por orden cronológico (más riguroso en M2 que en M1), ya llevan sus títulos definitivos. Es más, la última página del segundo cuaderno incluye un índice de los títulos (o de los primeros versos) y les asigna un número. Habiendo alcanzado cierto grado de elaboración, no aparecen sin embargo todos en la forma definitiva que les conocemos en las dos ediciones mexicanas. Pero, un tercer soporte, que no se ha tenido en cuenta hasta ahora, presenta en sus primeras páginas las mismas características que las observadas en los cuadernos "L'incomparable". Se trata de otro cuaderno de tipo escolar -como los otros, fácil de conseguir en cualquier "papelería" de Dijelfa o en el material de oficina que se utihzaría en la enfermería- titulado "Normandie", conservado en la BDCV. En él, con la misma letra aplicada, están copiados otros ocho poemas con fechas del 1 al 10 de mayo que constituyen así la exacta continuación cronológica de los textos de M1 y M262. Por lo tanto,

61 Cuadernos de tipo escolar con tapas rosas, blandas, cien páginas cuadriculadas, margen a la izquierda y tabla de multiplicar en la última página de la cubierta (FMA, C 4-10 y C 4-11.)

62 "Normandie" (BDCV, c. 12, v. 36), cuaderno de tapas anaranjadas más rígidas que las de los cuadernos anteriores, con viñeta del barco Normandie. El último poema de M2 es "Defensa de la calle de Rubiols" (inédito, 28 de abril de 1942) y los que figuran en las primeras páginas del cuaderno "Normandie" son los siguientes: "Nubes mañaneras" (1 de mayo de 1942, incluido en $D j 2$, en "Amaneceres", 38, sin modificaciones); "España, Prometeo" (2 de mayo de 1942, con correcciones; $D j 2,39$ ); "Viento viejo" (¿30 de abril de 1942?, no incluido en $D j 2$ ); "Alta calandria fija" ( 4 de mayo de 1942?, sin correcciones en $D j 2,1$, pero con fecha del 4 de mayo de 1941 y supuestamente escrito en Le Vernet); "Grita" ( 6 de mayo de 1942, con pocas modificaciones en $D j 2$, 40); "Lluvia" (6 de mayo de 1942, no incluido en $D j 2)$; "Vals lento" ( 8,10 de mayo de 1942, tampoco incluido en $D j 2$ ) y "Mora" (10 de mayo de 1942, con escasas modificaciones en $D j 2,41$ ). Las restantes páginas del cuaderno 
teniendo en cuenta sus características materiales comunes y su probable coincidencia temporal, son tres y no dos los cuadernos que conforman lo que se podría llamar el manuscrito "M1" y que, si fuera necesario precisar, se podría numerar Mla, M1b (FMA) y Mlc (BDCV), reservando la abreviación M0 para los manuscritos anteriores.

A pesar de que en M1 (a-b-c) varios son los textos que no alcanzan su forma definitiva, resulta pues claro que lo logrado dentro del campo parece a Aub una etapa satisfactoria. Aprovechando las condiciones materiales de las que dispone en la enfermería (escribir en cuadernos supone disponer de una mesa), hace lo que no le permitiría la incomodidad de una tienda marabú ni la obligación de trabajar el esparto. Se aplica a recoger, terminar y pasar en limpio los borradores dispersos en sus diversas libretas, sin dejar de modificar o corregir lo que le sigue pareciendo inadecuado. Esboza de esa forma un poemario artesanal, completando M1b con un índice y la numeración de los poemas. Todo ello permite comprender mejor por qué, el 3 de mayo, pudo proponer a Rolland-Simon enviarle "versos" ( ¿los de Mlb?) para que se publicaran, traducidos, en Fontaine. Su carta coincide con los días -primera quincena de mayo- en que, sin saber que saldría del campo poco después, termina de componer y transcribir los poemas de Mlc. También se puede constatar que los textos más vindicativos (43 a 46) no figuran en ninguno de los tres cuadernos, lo que parece confirmar la hipótesis anterior en cuanto a su transcripción en Casablanca (o eventualmente en México).

Pero, a este inventario de los manuscritos procedentes de Djelfa, hay que añadirle otro, aunque sea apócrifo. Según de-

contienen un evidente esbozo de "El poema de Aïn Sebaa", con letra mucho menos legible y abundantes correcciones, como si, después de ser la continuación, probablemente en Dịelfa, de M1 y M2, este cuaderno hubiera, en Casablanca, servido de borrador obviamente anterior a las copias mecanuscritas de dicho poema que figuran en el archivo de la FMA (C 22-1) o en el de la BDCV. (c. 8, v. 23). "Alta calandria fija", que figura en el cuaderno "Normandie" proporciona un buen ejemplo de las dificultades planteadas en el momento de ubicar los poemas en un calendario preciso: $D j 2$ le otorga una fecha (4 de mayo de 1941) diferente de la que aparece en los manuscritos (4 de mayo de 1942) y su procedencia también resulta problemática: en "Nota para la segunda edición" (Dj2, p. 9) dice Aub que escribió dicho poema (con otros) en Le Vernet pero la fecha indicada (4 de mayo de 1941) corresponde a su detención en Roland Garros. Por otra parte, el 4 de mayo de 1942 Aub se encontraba en Djelfa... 
claraciones del propio Aub -ahora totalmente descartables, ya que se conoce perfectamente la existencia de M0 y M1 y su punto de llegada, los archivos de la BDCV y de la FMA-, el único manuscrito que pudo salir del campo sería el que aparece en la segunda de las seis fotografías incluidas en el poemario. Esta fotografía reproduce, de un solo lado, una hoja de tamaño reducido donde lo que se ve escrito, en letra tan microscópica que resulta ilegible para cualquiera, son, siempre según las indicaciones del poeta, los veintisiete poemas de la edición de 1944. En la solapa del libro, donde figuran los comentarios explicativos de cada fotografía, el que corresponde a este extraño documento reza así: "Fotocopia [sic] del manuscrito de este libro, tal como logré sacarlo del campo". En la segunda edición desaparecen los comentarios pero son dos las hojitas "fotocopiadas", dando a entender con cierta lógica que a mayor número de poemas (cuarenta y siete en 1970) debe corresponder un manuscrito de mayores dimensiones. Con lo cual el pacto establecido desde 1944 empieza a resquebrajarse: la primera hojita no era "el" manuscrito sino sólo una parte. Es más: las palabras del autor anteriormente citadas no sólo definen el documento en cuestión como el único manuscrito que pudo sacar del campo sino que al mismo tiemoo sugieren -"tal como logré sacarlo"- que no pudo salir sin algún ardid, lo que parece conferirle un carácter clandestino. Conoeido ahora gracias a un minucioso estudio realizado por María José Calpe, archivera de la FMA, el contenido de las dos hojitas -en realidad una sola representada recto verso en la segunda edición del poemario- desmiente tajantemente que se trate de "el" manuscrito de Diario de Djelfa. En una carilla caben once textos, dos inéditos y nueve incluidos en $D j 2(11,9,13,10,12,7,8,6,21$, en este orden), en la otra, el texto entero de "Toda una historia" (19) y un tercer poema no inclmido en el poemario ${ }^{63}$. O sea que, contrariamente a lo que al lector se le insta a creer, la "fotocopia" única reproducida en $D j 1$ y la doble de $D j 2$ no incluyen los contenidos de estas ediciones. En cuanto al carácter "clandestino" de la hoja, el estado de perfecta conservación en que se encuentra en la FMA hace dudar de que Aub tuviera que sacarla escondida en su anatomía, como

63 Véase, María José CALPE, "El manuscrito «clandestino" de Djelfa", Sala de Espera. Boletin informativo de la Fundación Max Aub, Segorbe, enero de 2003, núm. 5, 17-19. 
escriben algunos estudiosos ${ }^{64}$. Precaución además innecesaria ya que, al salir del campo, Aub se pudo llevar, probablemente en su maleta, las libretas y los cuadernos. En realidad, lo que hace el autor al recurrir a esta estratagema peritextual tiene que ver con lo que, al hablar de literatura de los campos, Semprún consideraría un "artificio". En varias de sus novelas que remiten al campo de concentración de Mauthausen donde estuvo deportado, el escritor franco-español insiste en su preocupación en cuanto a la necesidad de contar bien aquellas vivencias comunes a miles de hombres y a la forma de conferirles densidad literaria o artística, que es lo mismo. Así, en L'Écriture ou la vie, para otorgar la literariedad necesaria a lo que, sin ella, se quedaría en mero testimonio y para "suscitar la imaginación de lo inimaginable", Semprún puntualiza: "Contar bien, quiere decir: de manera que nos entiendan. No lo conseguiremos sin un poco de artificio" 65 . Aub era consciente de ello como se ve en el cuento epistolar "El cementerio de Dielfa" [1965] en el que Pardiñas, el supuesto autor de la "carta", escribe:

Si digo las cosas como son, parece poco: hay que buscar mojones de referencia e irlos atando con una cuerda. Las palabras son tan pobres frente a los sentimientos que hay que recurrir a mil trucos para dar con el reflejo de la realidad... El buen paño en el arca se pudre. Hay que arreglar los escaparates ${ }^{66}$.

${ }^{64}$ Por ejemplo, E. Nos Aldás que cita a José Luis Morro: "El 18 de mayo de 1942 Aub sale de Djelfa, sacando «dentro de su cuerpo» las pequeñas hojitas del Diario de Djelfa... y va camino de Casablanca" (op. cit., p. 109). En una nota a pie de página, precisa que el primer eslabón de la cadena informativa (Bernardo Giner de los Ríos, José Luis Morro y ella) fue el propio Aub, lo cual no constituye, ni mucho menos (más bien al contrario en este caso), una prueba de veracidad. José Luis Morro, después de escribir que "Dentro de su cuerpo [Aub] logró sacar su Diario de Djelfa", añade en una nota: "Conversación del autor con una persona que prefiere guardar el anonimato" ("Max Aub, ¿un exilio diferente?", en El exilio literario español de 1939. Actas del Primer Congreso Internacional [Bellaterra, 27 de noviembre-1 de diciembre de 1995], ed. M. Aznar Soler, GEXEL-Cop d'Idees, San Cugat del Vallès, 1998, t. 1, p. 174). Soldevila (op. cit., p. 77) y Malgat (op. cit., p. 198) parecen aceptar para el extraño documento ese destino clandestino.

${ }^{65}$ Jorge Semprún, L'Écriture ou la vie, Gallimard, Paris, 1994, pp. 166 y 165 ; la traducción es mía.

${ }^{66}$ Enero sin nombre. Los relatos..., p. 335. No otra cosa preconiza, por su lado, RoBert ANTELme: véase L'Espèce humaine [1957], Gallimard, Paris, 1978, p. 302. 
Por otra parte, este proceder aubiano anuncia también lo que en otros libros cobrará un valor lúdico: las fotografías trucadas de Jusep Torres Campalans ${ }^{67} \mathrm{y}$, al mismo tiempo, los supuestos manuscritos de Imposible Sinai, "encontrados en bolsillos y mochilas de muertos árabes y judíos de la llamada «guerra de los seis días", en 1967"68 o el de Manuscrito cuervo cuyo fingido editor, J. R. Bululú, dice: "Cuando salí, por primera vez, del campo de concentración de Vernete y llegué a Toulouse, en los últimos meses de 1940, encontré en mi maleta un cuaderno que no había puesto allí... Ignoro quién colocó aquel cuaderno en mi equipaje". Luego, en un divertido cruce de pistas, la descripción que hace Bululú de este cuaderno corresponde en buena parte a la de los soportes de Mla-b: “...34 páginas de un cuaderno de 48 , tamaño $18 \times 24 \ldots$ Las cubiertas son color rosa y llevan impresas atrás la tabla de multiplicar. $\mathrm{Al}$ frente se lee L'incomparable, y, abajo 48 páginas" 69 . E1 manuscrito miniaturizado es por consiguiente um señuelo, una afabulación más palpitante que la "simple" verdad de los manuscritos archivados, quizás más necesaria ${ }^{70}$, y cuya perfecta realización hace que resulte fácil caer en la trampa de una clandestinidad supuestamente indispensable en el momento de escribir los poemas y, luego, de salir del campo.

Lo que también interesa es que al atribuir a Diario de Djelfa un manuscrito cuya representación material refuerza la historia ficticia de clandestinidad que se le atribuye, Aub no sólo entronca con la amplia y larga tradición del manuscrito apócrifo, perdido, reencontrado, sino que, al mismo tiempo, se anticipa a algunos sucesos, reales éstos, de la literatura de los campos con sus no escasos manuscritos escondidos o perdidos, olvida-

${ }^{67}$ Novela en la que Torres Campalans proporciona, en el estilo elíptico propio de AUB, una explicación clara y sencilla para justificar la presencia de este tipo de "mentiras" en el arte: "El arte, ¿verdad o mentira? ¿Importa? No, si es arte, es verdad" ( Jusep Torres Campalans [1958], Destino, Madrid, 1994, p. 54).

68 Max Aub, Imposible Sinaí [1982], introd., ed. y notas E. Londero, Fundación Max Aub, Segorbe, 2002, p. 49. También en Obras completas, t. 1, pp. 289-322.

${ }^{69}$ Max Aub, Manuscrito cuervo [Sala de Espera, 1948-1950, núms. 24 a 27], introd., ed. y notas J. Pérez Bowie; epílogo J. M. Naharro-Calderón, Fundación Max Aub, Segorbe, 1999, pp. 46 y 47, respectivamente.

${ }^{70}$ ROBERT ANTELME, refiriéndose a lo que contaban los sobrevivientes de los campos nazis, escribía: “...il faudrait tout croire, mais la vérité peut être plus lassante à entendre qu'une fabulation" (op. cit., p. 302). 
dos y reaparecidos años después, casi siempre clandestinos ${ }^{71}$. Aclarada la estratagema, a pesar de todo sigue siendo un misterio cómo se pudo fabricar dicho manuscrito miniaturizado. Su realización en un lugar como Djelfa, y más aún en un campo de internamiento, plantea muchos interrogantes, supone la utilización de un material tan sofisticado que, en ausencia de un análisis codicológico (papel y tinta) y grafológico, lleva a formular la hipótesis de su fabricación en Casablanca o en México. Y, aunque ello no se confirmara, quedaría sin embargo claro que el documento "clandestino" no es el manuscrito del poemario y resultó innecesario en el momento de salir del campo. Aub, que en el "Cuaderno verde", prestándole su pluma a Jusep Torres Campalans, escribiría: "No creer jamás que los demás son bobos, al contrario: decir para iguales. Si se junta lo supuesto verdadero con lo falso, dar pistas, dejar señales para que todos hallen el camino del alma" 72 , no parece haber dejado ninguna pista, ninguna señal al respecto.

En Djelfa, desde fines de diciembre de 1941 (antes, no parece haber escrito mucho) hasta mediados de mayo de 1942, o sea en cuatro meses y medio, Aub encontró tiempo para escribir

71 Véanse, para lo que concierne a los manuscritos apócrifos en la literatura española de los campos, a Michael UGARTE, "Testimonios del exilio: desde el campo de concentración a América", en El exilio de las Españas de 1939 en las Américas " ¿A dónde fue la canción?" (coord. J. M. Naharro-Calderón, Anthropos, Barcelona, 1991, pp. 43-62); Francie Cate-Arries, Spanish culture behind barbed wire. Memory and representation of the French concentration camps, 1939-1945 (Bucknell University Press, 2004, pp. 182-184) y, entre otros, el ejemplo concreto de Agustí Cabruja-Auguet, autor de La ciudad de madera donde declara: "Yo no soy el autor de este libro. El autor, el verdadero autor se desconoce... Yo no he hecho nada más que corregir, enmendar y ordenar, como lo hace el jardinero con los rosales de su jardín, una serie de cuartillas que, envueltas en un pliego deshecho y medio enterrado, encontré cierto día en los arenales de la playa de Argelès-sur-Mer. / En una hoja suelta, escrita a lápiz, el autor exponía los motivos por los cuaies veíase impulsado a desprenderse de su obra... ;El desdichado joven iba a poner fin a su vida!" (Editorial Vértice, México, 1947, p. 9). En lo que concierne los campos nazis, remito a los manuscritos realmente escondidos en el suelo de Auschwitz por algunos miembros del Sonderkommando, descubiertos y publicados muchos años después (Des voix sous la cendre. Manuscrits des Sonderkommandos d AuschwitzBirkenau, Mémorial de la Shoah-Calmann-Lévy, Paris, 2005) o a lo que ocurrió con los poemas de JEAN CAYroL, escritos clandestinamente en Mauthausen, perdidos, encontrados, devueltos a su autor por un alemán anónimo en 1955 y, por fin, publicados (nota prelim. del editor, Alerte aux ombres 1944-1945, Editions du Seuil, Paris, 1997, p. 5).

72 MAX AUB, Jusep Torres Campalans, p. 262. 
un centenar de textos y dejar unos ochenta de ellos limpiamente copiados en M1. Proeza que es de subrayar en un lapso tan corto. Jean Cayrol, en las condiciones probablemente mucho más duras del campo de Gusen, dependencia de Mauthausen, escribió casi doscientos, "clandestinamente «en la penumbra sin releerse", en hojas de papel de fumar"73, pero lo hizo entre 1943 y 1945; Varlam Chalamov compuso unos cien, en el Gulag de la Kolyma, en circunstancias que él mismo describe y que permiten entender que lo hizo en un período aún más largo:

De 1937 a 1956 he vivido en los campos y en exilio. Las condiciones del Norte extremo excluyen la posibilidad de escribir y de conservar relatos y poemas -suponiendo que uno quiera hacerlo. Durante cuatro años no tuve ni libros ni periódicos. Después ocurrió que de vez en cuando se podía escribir y guardar poemas. Mucho de lo escrito - un centenar de poemas- ha desaparecido para siempre. Algo sin embargo se ha salvado. En 1949 , trabajando como ayudante de médico en un campo... durante todo mi tiempo libre escribía: en el reverso y en las hojas en blanco de la farmacopea, en hojas de papel de embalaje, en bolsitas de papel ${ }^{74}$.

Pero Aub pudo escribir en condiciones generales mucho más propicias, las de la enfermería de Djelfa: tiempo libre, puesto de trabajo ("debajo de la ventana una mesa coja, un cuaderno, un tintero, un palillero", cf. supra), material más o menos adecuado (libretas propias o adquiridas, cuadernos "L'incomparable" y "Normandie", tal vez provenientes de la misma enfermería), elementos todos que sugieren menos necesidad de clandestinidad que en Gusen o en la Kolyma y que transformarían en ficción cualquier manuscrito subrepticio escrito en soportes materiales tan volátiles como el papel de fumar o tan en el último momento rescatados de la papelera o de la basura. El papel del supuesto manuscrito clandestino que con tanta minucia describe María José Calpe, se "parece" al de fumar, pero no lo es ni por su tamaño ni por su consistencia.

${ }^{73}$ LiONEL RichaRd, "Jean Cayrol. Les temps obscurs sont toujours là", Le Magazine Littéraire, enero de 2005, núm. 438, p. 52 (monográfico dedicado a la literatura de los campos).

74 Varlam Chalamov, "Fragments de mes vies", Cahiers de la Kolyma, tr. C. Mouze, Marcel Nadeau, Paris, 1991, p. 14; la traducción es mía. 
UN ESTATUS ESPECIAL

Obviamente, no se les podía haber escapado a Caboche y a los demás responsables del campo que ese "escritor" 75 nacido en París, que compartia con unos cuatrocientos presos la nacionalidad española, tenía el perfil ideal para ejercer tareas burocráticas. No sólo hablaba francés como si siempre hubiera vivido en la calle de Trévise (noveno distrito de París), sino que también lo escribía, como cuando, desde su llegada al campo, redactaba él mismo en francés las cartas que dirigía a los más altos responsables de la jerarquía administrativa para solicitar su liberación y se le dejaba pasarlas a máquina.

Conviene observar también que, así como ocurría desde su internamiento en Le Vernet ${ }^{76}$, a pesar de lo declarado en la denuncia anónima inicial y de la habitual precisión quisquillosa de los documentos administrativos o policiales de Vichy al respecto, en Djelfa Aub nunca fue declarado judío, sin que se sepa si se debe a otra cosa que a la simple repetición mecánica de lo transcrito en documentos anteriores. No obstante, el hecho no deja de sorprender en un período en que aquel régimen daba muestras crecientes de antisemitismo. La lista de los recién llegados a Djelfa que manda Caboche a sus superiores el 29 de noviembre de 1941 es un buen ejemplo de precisión burocrática al respecto. Consta de sesenta y ocho nombres entre los que el de Aub aparece con la mención "español" mientras que, para otros treinta y tres presos, la nacionalidad sólo es un calificativo de la mención racista "judío": "juif allemand", "juif autrichien", "juif roumain", "juif soviétique", etc. ${ }^{77}$ En sus informes el coronel Lupy recurre a una formulación del más habitual, elíptico y abrupto estilo administrativo. $\mathrm{Al}$ principio de octubre de 1942, las cúras que da referentes a Djelfa se presentan en la forma siguiente, por ejemplo: "Allemands 39 dont 16 juifs", "Autrichiens 14 dont 11 juifs", "Espagnols 410 dont 1 juif",

${ }^{75}$ Profesión mencionada por Caboche en su carta del 31 de diciembre al teniente coronel Brot (doc. cit.)

76 "En el presente caso, debo señalar que el llamado AUB Max, destinatario de una de esas cartas no es de raza judía" (carta del Prefecto del departamento del Ariège al Ministro del Interior, citada por José MARÍA Naharro-Calderón, "De «Cadalso 34» a Manuscrito Cuervo: el retorno de las alambradas", epílogo a Manuscrito Cuervo. Historia de Jacobo, p. 211).

77 Documento dirigido por "Le Directeur du CSS" a "Monsieur le Commandant Militaire du Territoire de Ghardaïa, Laghouat" (CAOM, doc. cit.). 
"Polonais 146 dont 55 juifs", "Soviétiques 85 dont 37 juifs". Para las mismas nacionalidades, otro informe del mismo Lupy a fines de diciembre de 1942 indica lo siguiente: "Allemands 35 dont 15 juifs", "Autrichiens 10 dont 9 juifs", "Espagnols 388 dont 1 juif", "Polonais 102 dont 26 juifs", "Soviétiques 86 dont 38 juifs" 78 . A pesar de esos precisos y constantes recuentos discriminatorios impuestos por Vichy, Aub es, en Djelfa, "escritor", "español" a secas y "católico", lo cual le evita padecer los malos tratos sufridos a veces por algunos judíos del campo o ser privado de trabajo y, consecuentemente, del suplemento alimenticio tan necesario, el "cascrut" del poema "Epitafio" (21).

Es más, sus actividades conocidas, más o menos "clandestinas" (tomar apuntes en sus libretas, escribir poemas, organizar veladas teatrales y poéticas), realizadas a escondidas o no tan prohibidas, no parecen haberle impedido beneficiarse de apreciaciones positivas por parte de los distintos estamentos de la administración colonial. A raíz de la solicitud de liberación que presenta en diciembre de 1941 y de la subsiguiente reacción del Gobierno general de Argelia el 19 del mismo mes pidiendo información sobre la conducta del preso español, Caboche manda a Laghouat un documento en el cual, después de haber calificado a Aub de "católico", añade que el preso en cuestión "[d] lesde su llegada al Centro [CSS1, no ha sido objeto de ninguna observación desfavorable" 79 . El 10 de enero, los servicios competentes del Gobierno general transmiten a Vichy el parecer del teniente coronel Brot, comandante militar del territorio de Ghardaïa del cual dependía Djelfa, y apoyan la solicitud: "Compartiendo la manera de ver del teniente coronel Brot, estimo como él que sería conveniente autorizar la liberación del internado en cuestión y su transferencia a Casablanca con vistas a su salida para México" 80 . En los archivos consultados no

78 Informes del coronel Lupy (CAOM) donde, además, excepto para los "soviéticos", se puede constatar la clara disminución del número de presos. No tengo datos precisos de quién sería el español declarado como judío. JaCoB Oliel proporciona para Djelfa, sin más precisiones, dos nombres de judíos españoles: Moïse Dadon Coen y Fernando Mayo Munos (sic) (Les camps de Vichy. Maghreb-Sahara 1939-1944, Les Éditions du Lys, Montréal, 2005 , pp. 173 y 181 ).

79 Carta del "Directeur du CSS" a "Monsieur le Commandant militaire du territoire de Ghardaïa. Laghouat": "Depuis son arrivée au Centre, n'a fait l'objet d'aucune remarque défavorable" (CAOM; MALGAT, op. cit., p. 107).

${ }^{80}$ Nota del Gobernador General de Argelia a "Monsieur le Directeur de la Sécurité Générale"; firmada: "Thouvenin, sous-chef.du service des Affaires 
aparecen indicios de cambios en la actitud de Aub, ni apreciaciones contrarias a las anteriores, aunque ello no impide que pudieran haber existido. En todo caso, resultaría interesante saber algo más sobre las razones que motivaron que al escritor se le mandara, según él declara, varias veces al campo especial, dura medida disciplinaria, orgullosa y solidariamente reivindicada en sus declaraciones mexicanas (cfisupra). Pero si Aub pudo tener, después de diciembre o enero, un comportamiento merecedor de dicho castigo, uno no se explica muy bien cómo podía justificarse la carta ya citada del 28 de febrero de 1942 al Gobernador general de Argelia en la que solicitaba autorización y visa para ir a Casablanca y, luego, a México, ni cómo, poco tiempo antes de salir de Djelfa, se le concedió el sorprendente permiso para sacar fotos dentro del campo, prestándole además una máquina fotográfica y un carrete. Menos aún considerando que algunos meses antes toda la jerarquía, de Dijelfa a Argel, se tuvo que movilizar para recuperar unas fotos con las que un teniente llamado Carrignon, miembro de la dirección del campo, quiso chantajear a Caboche ${ }^{81}$. Contradiciendo en gran parte sus afirmaciones en cuanto al carácter clandestino de las cinco fotos que acompañan el "manuscrito" miniaturizado en Diario de Djelfa, Aub proporciona en "Campo de Djelfa, Argelia" esta información jamás publicada por él:

Hacía nueve meses que 250 españoles habían pedido su repatriación, nueve meses de decirles que no había dificultad alguna para ello. Nueve meses más de trabajos forzados. El 20 de mayo vino la orden de partida. Pedí permiso para fotografiar algunos compañeros que regresaban a España. Me lo concedieron, dejándome la máquina y un carrete con la obligación de darlo a revelar al mando del campo. Tiré dos carretes, el uno me lo quedé y son las fotografias que acompañan estas líneas ${ }^{82}$.

indigènes et du personnel militaire": "Partageant la manière de voir du Lieutenant Colonel Brot, j'estime comme lui qu'il y aurait avantage à autoriser la libération de l'intéressé en cause et son transfèrement sur Casablanca en vue de son départ au Mexique" (CAOM).

${ }^{81}$ Basándome en diversos documentos conservados en el CAOM, analizo este revelador episodio en "Max Aub et la fictionnalisation des traces...".

82 "Campo de Djelfa, Argelia" (doc. cit.). Las últimas palabras de esta cita ("son las fotografias que acompañan estas líneas") parecen confirmar que "Campo de Djelfa, Argelia" sirvió de borrador para ":Yo no invento nada!". La publicación de estas líneas explícitas, en 1943 en la Revista Todo, hubiera desmentido clara y anticipadamente lo que se afirmaría en 1944 en Dj1: "Las 
Estas líneas, "pistas" o "señales", contradicen lo proclamado en $D j 1$ y reiterado en $D j 2$, limitándolo al subterfugio del segundo carrete. Buen ejemplo de mezcla de "lo supuesto verdadero con lo falso" a la que se añaden un problema de fecha (20 de mayo, ¿error o señuelo?) y el episodio de los 250 españoles repatriados, documentado en los archivos donde se cuenta, evidentemente, de otra forma ${ }^{83}$.

En cuanto a la propia liberación del escritor, fuera de lo indiscutible de la fecha establecida, las circunstancias rocambolescas que la rodearon dejan perplejo al que quiere entenderlas. Caboche firma la orden de liberación el domingo 17 de mayo, satisfaciendo lo solicitado en un telegrama recibido dos días antes (el viernes 15), proveniente de un comisario jefe de la policía administrativa de Casablanca, funcionario que, por su situación territorial y el cuerpo al que pertenece, lógicamente no puede tener autoridad sobre un militar (comandante de reserva), director de un campo en Argelia ${ }^{84}$. Caboche no parece inmutarse, actúa sin dilación ninguna y, después de haber firmado la orden de liberación el 17 sin la autorización de su:jerarquía (el teniente coronel Brot en Laghouat, los servicios competentes del Gobierno general en Argel), sólo informa a Brot

fotografías que aquí se publican son las únicas que, sin permiso del mando, se hicieron en el campo de Djelfa" (solapa de la cubierta), y se repetiría en Dj2: "Las fotografías son las únicas que pudieron tomarse, clandestinamente como es de suponer, en aquel entonces del, para mí, famoso lugar" ("Nota para la segunda edición", p. 9). Está claro que las fotografias del poemario no fueron las únicas sacadas en Djelfa, ni lo fueron en forma clandestina.

$83 \mathrm{Al}$ final de su informe (primavera de 1942), el inspector Jean-Faure escribe: “...plus de 240 [Espagnols] veulent rentrer en Espagne. / Le Gouvernement général ne voit aucun inconvénient à leur départ, bien au contraire. Ce départ avait même été décidé pour le 12 février 1942, tous les moyens de transport prévus pour les mener à la côte et les embarquer pour l'Espagne, lorsque leur Consul Général a fait une démarche auprès du Gouvernement Général afin d'empêcher ce départ /... / Je n'ai pu que leur dire que l'Administration française envisage favorablement leur départ simplement subordonné à l'agrément de leur consul. / J'estime qu'il conviendrait d'insister auprès du gouvernement espagnol pour que ces 240 internés dont la subsistance demeure à la charge du Trésor -environ 300 frs par mois et par interné- soient renvoyés chez eux" (AN Paris).

${ }^{84}$ Salvo que se trate de un error de mi parte, no figura el telegrama en el CAOM. Sólo se conoce su existencia por la referencia que Caboche hace de él en su comunicación a Brot, el 18 de mayo: "Référence: Télégramme officiel n ${ }^{\circ} 233$ du 15 courant de M. le Commissaire Chef de la Police administrative à Casablanca" (CAOM). 
de la salida de Aub el lunes $18^{85}$, fecha en que efectivamente éste abandona el campo. El 20, el teniente coronel transmite la información a la Dirección de los Territorios del Sur (Gobierno general de Argelia) que la recibe el 27 y la envía a Vichy con una anotación manuscrita que, por si acaso, señala su propia falta de responsabilidad en la irregularidad del proceso: "copia transmitida para información al Señor Director de la Seguridad General. La Dirección de los Territorios del Sur no ha sido informada de la liberación del interesado" 86 . Cumpliendo con su hoja de ruta, indicada en el documento del 17, Aub pasa por Uxda (Marruecos) donde llega el 20 y se le retiene unas horas en el momento de pasar el puesto fronterizo: ¿qué intenta averiguar la policía?, ¿adónde llama por teléfono?, ¿qué información espera y consigue? Aquel día, el teléfono parece haber tenido un particular protagonismo que no había tenido unos días antes en Djelfa. En la libreta "Le pratique", Aub escribe "Espera" (Uxda, 20-5-42), uno de los poemas compuestos en aquellas horas de difícil incertidumbre. Unos juegos semánticos y homonímicos, muy en la línea aubiana, evocan la fragilidad del destino ("hilo"), el miedo de que el "alambre" telefónico funcione como alambrada y el timbre del aparato como ajusticiamiento:
¡Sentir colgada nuestra vida al son de un hilo y azar de los azares y hadas!
Parecer el teléfono alambradas, cada timbre garrote y puñalón ${ }^{87}$.

Pero el 27 de mayo, cuando sale para Vichy la noticia de la liberación de Aub, éste ya se encuentra, desde hace unos días, en Casablanca donde, aparentemente, no se le busca con mucho empeño a pesar de que, casi al mismo tiempo, el 26, Vichy informa a Argel que el escritor español (y otros siete presos de Djelfa) no pueden ser liberados ${ }^{88}$. En una carta dirigida a Rafael Prats

${ }^{85}$ Respetuoso del descanso dominical, ¿habrá esperado Caboche que terminara el fin de semana para informar a su jerarquía? Sin embargo, él mismo firma la orden de liberación de Aub el domingo 17...

86 "Copie transmise pour information à M. le D[irecteur] de la S[ûreté] G[énérale]. La Direction des T[erritoires] du S[ud] n'a pas été informée de la libération de l'intéressé" (CAOM).

${ }^{87}$ Libreta "Le pratique" (BDCV, doc. cit.): segundo cuarteto del soneto.

${ }^{88}$ Véase el documento correspondiente reproducido por MALGAT ( $o p$. cit., p. 109.) 
Ribelles, Aub comenta lo que considera como una casi huida del campo de Djelfa, sin aportar muchas aclaraciones:

Me medio escapé de este último, porque no se puede llamar escapar teniendo la complicidad de uno de los guardianes principales, en ese caso el de un policía degaullista; lo que me hizo perder el barco que me tenía que llevar a Norteamérica fue una detención de unas horas en Uxda... ${ }^{89}$.

Lo que parece confirmarse aquí es tan sólo la complicidad del comisario de policía de Casablanca, autor del telegrama del 15 de mayo. Pero no se llega a comprender del todo cómo un simple telegrama, incluso "oficial"90, pudo permitir de repente, pese a las reglas administrativas y militares más elementales, la liberación del extranjero Aub a quien Vichy consideraba todavía peligroso e indeseable. Sin embargo, el ardid, en el cual Bosques inevitablemente colaboraría ${ }^{91}$, resultó eficaz, pero pudo ser peligroso para los que lo concibieron o realizaron, inclusive para Caboche, tan respetuoso habitualmente de la jerarquía de la que dependía, transformado en actor esencial, aunque involuntario, de la casi huida de un preso bajo su responsabilidad. En

${ }^{89}$ Carta del 12 de agosto de 1970, reproducida por Aznar Soler en el pról. a Diarios (1939-1972) y Diarios 1939-1952, pp. 14 y 12, respectivamente.

${ }^{90} \mathrm{La}$ orden de liberación firmada el 17 de mayo por Caboche se expide "[en] exécution du télégramme officiel $n^{\circ} 233$, du 15 courant" (CAOM, doc. cit.) La carta mandada a Brot el día siguiente lógicamente remite al mismo documento cuyo carácter officiel podría ayudar a explicar la precipitación de Caboche. Éste, como es habitual en ese tipo de correspondencia administrativa, parece retomar algunos de los términos de dicho telegrama: "Aub doit se rendre à Casablanca d'urgence en vue de son embarquement pour le Mexique" (CAOM, doc. cit.)

${ }^{91}$ Aư declaró a André Camp: “...en 1942, grâce à un policier gaulliste, j'ai pu comme ça arranger, plus ou moins et toujours grâce aux Mexicains, ma sortie disons... plus ou moins clandestine du camp. Car les Allemands n'ont rien su. C'est ce qui m'a d'ailleurs valu d'être arrêté, à Oujda, entre le Maroc et l'Algérie, où j'ai passé quelques heures assez difficiles en pensant que j'allais être de nouveau envoyé à Djelfa. Mais j'ai tout de même pu passer" (cuarta de las seis entrevistas mantenidas con A. Camp para la emisora "France-Culture" en mayo de 1967; transcrita por MALGAT en su tesis doctoral: Max Aub et la France ou l'espoir trahi?, Université Paris X-Nanterre, 2002, t. 2, p. 97). Por su lado, José LuIs Morro cita un documento de Aub conservado en la FMA: "Edmundo González Roa -enviado por Bosques a Casablanca- en complicidad insospechada con un jefe de policía, logró sacarme del campo de Delfa" ("Max Aub, cun exilio diferente?"). 
los archivos consultados, ningún documento alude a cualquier sanción disciplinaria a raíz de este desliz administrativo.

De por sí, a pesar de un estatus que le proporcionó algunos privilegios, lo vivido por Aub en Djelfa rebasa probablemente en penalidades todo lo experimentado en sus otras experiencias carcelarias, inclusive quizás en Le Vernet d'Ariège. Carece de sentido, por consiguiente, dejarse llevar por la tentación de cargar las tintas aportando (o repitiendo) datos erróneos que alteran la geografía y la historia. Situar Djelfa en una latitud o a una altura que no le corresponden ${ }^{92}$, apreciar las temperaturas generalizando máximas y mínimas poco fiables ${ }^{93}$, repetir que Aub tuvo que trabajar en la obra del transahariano ${ }^{94}$, alargar en varios meses su estancia en el campo, escribir que se esca-

92 Eugenia Meyer lo ubica "en pleno desierto del Sahara" ("Los años mexicanos de Max Aub”, Homenaje a Max Aub, p. 39). Corrigiendo sólo una de las dos erratas o equivocaciones de Aub (o de la mecanógrafa) en "Intervención del C. Max Aub..." (doc. cit.), E. Nos Aldás lo sitúa a "cuarenta kilómetros al sur de Argel [ $s i c$ ], a unos mil quinientos [en vez de «quiniemos»] metros de altura" (op. cit., p. 105). Para NAHARro-Calderón Djelfa estaría a 1400 metros ("Max Aub y los «universos concentracionarios", en Max Aub: enracinements et déracinements, p. 117, también en Homenaje a Max $A u b$, p. 113). La altura oficial de Djelfa es de 1144 metros; situado en una vertiente el campo podía estar a unos 1200 metros, altura confirmada en el informe de JEAN-FAURE: "Le camp de Djelfa, du territoire militaire de Gardhaia, créé en mars 1941, est situé á $1 \mathrm{~km}$ au nord de Djelfa, sur la rive droite de l'Oued Djelfa, á environ $1200 \mathrm{~m}$ d'altitude" (doc. cit.).

93 Retomando las indicaciones del autor ("Intervención del C. Max Aub..."), E. Nos Aldás habla en su tesis de "una temperatura nocturna en invierno de más de veinte grados bajo cero, mientras que en verano subía a más de cincuenta o sesenta grados" (op. cit., p. 105). Pero el propio "termómetro" de Aur es algo fluctuante: "Por la noche la temperatura baja a $-15^{\circ}$. Por el día... sube a $55^{\circ}$ y $60^{\circ}$ " ("Campo de Djelfa, Argelia"); "...temperaturas de más de $10^{\circ}$ bajo cero" ("En un acto contra el terror nazifascista"); "El termómetro refleja / ya más de diez bajo cero" ("In memoriam", 8). Suponiéndolas posibles, estas mínimas siberianas y máximas infernales, en el peor de los casos corresponderán a picos extremos, o más bien al recuerdo de extremas sensaciones térmicas de los presos desprotegidos, y en ningún caso a temperaturas corrientes a juzgar por las indicaciones meteorológicas de la zona de Djelfa (en caso de incredulidad, búsquese en Google, "Climatological normais of Dielfa"): observaciones que, sin embargo, no hacen del campo de Djelfa, con sus tiendas de campaña, un ameno campamento para turismo rústico.

94 I. Soldevila, op. cit., p. 42. E. Nos Aldás cita a tres autores que se refieren al transahariano (Soldevila, Pérez Bowie, Poniatowska) y escribe: "Sin embargo [Aub] no lo menciona en ninguno de sus textos testimoniales, además de que sería raro debido a su status" (op. cit., p. 107, n. 100.) Más raro aún debido a la distancia entre Djelfa y Colomb Béchar. 
pó teniendo que llevar escondido su "manuscrito clandestino" contribuye a un proceso de ficcionalización, quizás no siempre involuntario, en el que un escritor puede participar conscientemente pero que, en el caso del investigador, es señal de falta de indagación rigurosa o de artificiosa retórica hiperbólica. Más aún ${ }^{95}$, comparar las celdas del fuerte Caffarelli, otro lugar de castigo de los presos en Djelfa, con la famosa escalera de la cantera de Mauthausen es equiparar-movido por una indignación comprensible y compartida más que por datos que lo justifiquen- dos sistemas concentracionarios (el nazi y el de Vichy) que ofrecen grandes diferencias, de naturaleza o de grado ${ }^{96}$. Por si acaso, se añadirá que constatar y aceptar lo anterior es tan sólo tratar de atenerse a la verdad histórica, lejos de cualquier intento "revisionista". No le quita a aquel campo francés de Argelia ninguna de sus características ignominiosas, ni valor a Aub en su resistencia frente a la adversidad ni interés a Diario de Djelfa que, con otros títulos suyos, vincula al escritor español con los principales representantes europeos de la literatura de los campos. Pero en el caso de este poemario nos encontramos ante un hecho bastante excepcional: a pesar de la ficción de M2, los distintos estados de los verdaderos manuscritos autógrafos (M0 y M1) no se han perdido. Si se añaden las versiones mecanogra-

95 Valga otra vez el chiste, en homenaje a José de la Colina que lo inventó.

96 Naharro-Calderón va más allá de la difícil aunque a veces esclarecedora comparación entre "campos de internamiento" y "campos de concentración" (cf. Koestler, supra, pp. 404-405). Sin tomar en cuenta las importantes diferencias establecidas por los historiadores entre los distintos sistemas concentracionarios, hace una amalgama imposible entre campos franceses, campos de concentración nazis, campos de exterminio y escribe estas extrañas líneas en las que el uso de algunos términos es obviamente desproporcionado (inclusive en frases negativas) mientras otros parecen haber perdido el sentido preciso que se les atribuye en la historiografía especializada: "Sin cámara de gas, los campos franceses que visitó Aub contenían todos los ingredientes del exterminio... De alguna forma Djelfa poseía su escalera de la cantera de Mauthausen en las celdas de Caffarelli. En todo caso, el cadáver de El Málaga «horrendo de delgado, con los ojos abiertos, brillantes y salidos como birlas" bien podría estar amontonado entre aquellos millones de cadáveres del terror nazi". Luego, forjando algo como un extraño oxímoro, cuyo efecto es la banalización del genocidio judío, se refiere a una "especie de «solución final» ma non troppo" ("Max Aub y los «universos concentracionarios"”, en Max Aub: enracinements et déracinements, pp. 116 y 117 o en Homenaje a Max Aub, pp. 111-112). 
fiadas de la BDCV (M3 ${ }^{97}$ ), los investigadores de la literatura de los campos disponen del material necesario para llevar a cabo estudios genéticos susceptibles de hacernos penetrar, sobre todo en las condiciones especiales de Djelfa, en el espacio y el tiempo de una creación que, aunque testimonial, no deja de ser estética. En ese terreno ha adelantado César Núñez al ofrecer la edición crítica de treinta y dos poemas del ciclo de Djelfa, de los que veintiséis figuraban ya en la edición definitiva, la de $1970^{98}$.

BERNARD Sicot

Université Paris X-Nanterre

${ }^{97}$ M0, M1, [M2], M3: me parece que proponer esta numeración simplificadora para los distintos estados de los manuscritos tiene la ventaja de tomar en cuenta los ricos acervos complementarios de los dos archivos, el mexicano y el español, que el autor (o el destino) han separado.

98 Véase art. cit., pp. 291-347. 